\title{
Transcritical Carbon Dioxide Charge-Discharge Energy Storage with Integration of Solar Energy
}

\author{
Reyes Fernandez ${ }^{* 1}$, Ricardo Chacartegui ${ }^{2}$, Antonio Becerra ${ }^{3}$, Beatriz Calderon ${ }^{4}$, \\ Monica Carvalho 5 \\ ${ }^{1}$ Energy Engineering Department, University of Seville, Calle San Fernando, 4, 41004 Seville, Spain \\ e-mail: rfernandez30@us.es \\ ${ }^{2}$ Energy Engineering Department, University of Seville, Calle San Fernando, 4, 41004 Seville, Spain \\ e-mail: ricardoch@us.es \\ ${ }^{3}$ Energy Engineering Department, University of Seville, Calle San Fernando, 4, 41004 Seville, Spain \\ e-mail: jabv@us.es \\ ${ }^{4}$ Energy Engineering Department, University of Seville, Calle San Fernando, 4, 41004 Seville, Spain \\ e-mail: beatrizcagp@gmail.com \\ ${ }^{5}$ Center of Alternative and Renewable Energy, Federal University of Paraíba, Cidade Universitária, \\ s/n - Castelo Branco III, João Pessoa - PB, 58051-085, Brazil \\ e-mail: $\underline{\text { monica@cear.ufpb.br }}$
}

Cite as: Fernandez, R., Chacartegui, R., Becerra, A., Calderon, B., Carvalho, M., Transcritical Carbon Dioxide Charge-Discharge Energy Storage with Integration of Solar Energy, J. sustain. dev. energy water environ. syst., 7(3), pp 444-465, 2019, DOI: https://doi.org/10.13044/j.sdewes.d6.0235

\begin{abstract}
New and improved energy storage technologies are required to overcome non-dispatchability, which is the main challenge for the successful integration of large shares of renewable energy within energy supply systems. Energy storage is proposed to tackle daily variations on the demand side, i.e., storing low-price energy during off-peak or valley periods for utilization during peak periods. Regarding electrical energy storage, several technologies are available with different potentials for scalability, density, and cost. A recent approach for grid-scale applications is based on transcritical carbon dioxide charge and discharge cycles in combination with thermal energy storage systems. This alternative to pumped-hydro and compressed air energy storage has been discussed in scientific literature, where different configurations have been proposed and their efficiency and costs calculated. The potential of the concept has been demonstrated to be an economical alternative, including hybrid concepts with solar thermal storage. Even at low temperatures, the addition of solar energy has proved to be cost effective. This paper explores the effect of introducing solar-based high temperature heat on the performance of different configurations of "Transcritical carbon dioxide - thermal energy storage system" cycles. A base-cycle with 8-hour discharge time is compared with different layouts. Discussions include details on the models, parametric analyses -including solar technology alternatives-, and simulation results. Round trip efficiency of the base case, without solar support and at pressure ratio of 9.4 , is $52 \%$. When solar input is considered, the efficiency is above $60 \%$, increasing the turbine inlet temperature to $950 \mathrm{~K}$. Estimated levelized cost of electricity values are in the range of pumped hydro and compressed air energy storage, 90-140 USD/MWh in agreement with other works on this thermal storage technology. The global analysis shows clear advantages for advancing in the study and definition of this technology for exploitation of synergies at different power ranges, integrated with mid/high temperature solar power plants and with smaller-scale renewable installations.
\end{abstract}

\footnotetext{
* Corresponding author
} 


\section{KEYWORDS}

Energy storage, Hybrid energy storage, Solar, Carbon dioxide cycle.

\section{INTRODUCTION}

One of the main challenges for the dissemination of renewables is the necessity of reliable and cost-effective energy storage systems [1]. New and improved energy storage technologies are required to overcome the non-dispatchability, which is the main challenge for the successful integration of large shares of renewable energy into the grid. Energy storage is proposed to tackle daily variations on the demand side, i.e., storing low-price energy during low-demand hours and utilizing it during high demand hours, when energy usually becomes more expensive [2-4].

For electrical energy storage, several technologies are available, with different scalability, density, and cost potentials. Most advanced energy storage technologies for wind or Photovoltaics (PV) are based on batteries. In this sense, Pan et al. present sodium ion batteries as a solution for large-scale renewable energy storage, mainly thinking in renewables [5]. Other authors introduce these large energy storage systems as a solution for the large-scale integration of wind power into the grid [6] and the possibility these systems offer for optimizing this integration [7]. High-speed mechanical flywheels are also an available technology for large scale mechanical energy storage. Bolund et al. present an overview of these systems using high speed technology [8]. Supercapacitors are presented as a new class of reversible electrochemical energy storage in [9]. This technology is based on redox reactions and are being envisaged for several applications to complement the storage batteries. Pneumatic storage [10], pumped storage [11], or energy vectors such as hydrogen [12] are well-known technologies available for large scale energy storage and their role in future generation of energy storage system is not dismissed. For thermal solar energy, different options are available or under development, depending on the application [13]. In power plants, molten salts are commonly used for thermal energy heat storage [14] being integrated with the solar system under different integration schemes [15], although steam has also been used [16], Phase Change Materials (PCM) [17-18] and thermochemical storage [19-21] are currently under development. At small scale, residential-level sensible heat storage [22] and PCM [23-24], are the most widespread.

A recent approach for grid-scale applications is based on Transcritical Carbon dioxide $\left(\mathrm{CO}_{2}\right)$ charge and discharge cycles $\left(\mathrm{TCO}_{2}\right)$ in combination with Thermal Energy Storage Systems (TESS) [25], also feasible and interesting for residential applications. This alternative has been discussed in scientific literature, where different configurations have been proposed along with calculations of efficiency and costs [26-28]. The potential of the $\mathrm{TCO}_{2}$-TESS concept has been demonstrated to be an economical alternative at power plant scale [29], including hybrid concepts with solar thermal storage [26, 30]. The integration of heat pumps into thermal power plants for large-scale electricity storage capacities with round-trip-efficiencies of $60 \%$ was studied in [31]. A Pumped Thermal Electricity Storage (PTES) system with thermal integration composed by a vapour-compression Heat Pump (HP) and an Organic Rankine Cycle (ORC) was proposed in [32]. The comparison between a generic PTES system and a Pumped Cryogenic Electricity Storage (PCES) system was performed in [33] revealing better overall performances of a PTES system than those of a PCES system. In [34], a Thermo-Electric Energy Storage (TEES) system for large scale applications based on $\mathrm{CO}_{2}$ cycles and ground heat storage was presented.

This paper explores the effect of introducing solar-originated high temperature heat, or other renewable-originated heat, on the performance of different configurations of $\mathrm{TCO}_{2}$-TESS cycles. An integrated electrical/thermal energy storage concept is proposed 
herein, to store surplus electricity from the grid or at local level, combined with local renewable-originated thermal energy. The system is originally conceived to integrate solar energy but can be extended to biomass, such integration enables electrical and thermal energy to be stored at different temperature levels and from different sources, simultaneously or sequentially. The advantage is the capacity of adapting to a variety of different sources, using electricity and thermal energy. This paper builds upon these concepts and analyses, extending the concept to a mixed thermoelectric/thermal energy storage system, taking advantage of the different temperature ranges of both systems.

The proposed system can be integrated within solar thermal power plants that could be converted to electrical system regulation plants, but also in small size systems at residential or district level for integrating different distributed generation technologies. The effect of different layouts and thermal energy integration is discussed in this paper. A base cycle with 8-hour discharge time is defined and the effect of different modifications as TEES and solar TEES are studied. Details of the models, parametric analyses -including solar technology alternatives-, and results from simulations are discussed. Round-trip efficiencies for the base case, without solar support and a pressure ratio of 9.4, are 52\% for the cycle without solar input, and above $60 \%$ with solar support to increase turbine inlet temperature. Estimated Levelized Cost of Electricity (LCOE) values are in the range of those obtained for Pumped Hydro (PH) and Compressed Air Energy Storage (CAES), 90-140 USD/MWh [35, 36]. The global analysis shows the interest of advancing in the study and definition of this technology, probably integrated with solar power plants for exploiting synergies. The structure of the paper is the following. First, TEES concept is presented. Then, the different layouts under analysis are introduced and the parameters for performance evaluation and model assumptions are defined. Following, the results obtained from the numerical analysis are presented, without and with renewable resource support. Finally, a preliminary economic analysis is presented to identify $L C O E$ range for the analysed integrations.

\section{THERMOELECTRIC ENERGY STORAGE}

TEES is based on the dual operation of a heat pump (charge cycle)/thermal engine (discharge cycle) in the global system. During the charge cycle, a HP converts electricity to heat, which is stored, usually as sensible heat. In the discharge period, this heat is used in a thermal engine, where energy is partially recovered. This electricity storage concept was patented by Cahn [37], and has been widely studied recently [26, 27, 38]. Figure 1 presents the concept for heat exchange at variable and constant temperatures. These $T-S$ diagrams have been selected to show the relevance of adequate integration profiles for the charge/discharge processes [38]. An adequate heat exchange evolution design in both charge and discharge processes, with quasi-parallel evolution of temperature profiles between evolving streams, enables optimization of the energy storage process, maximizing its efficiency. This criterion restricts layout design and the selection of working fluids.
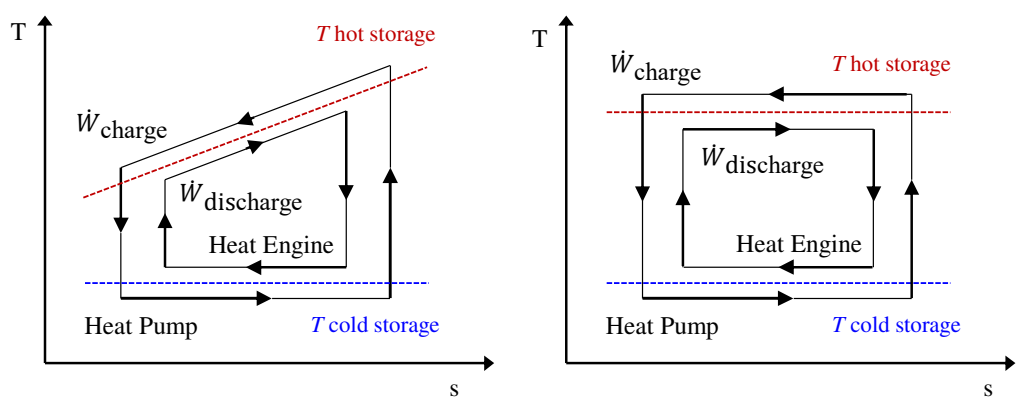

Figure $1 . \mathrm{TCO}_{2}$-TESS concept with well integrated temperature profiles 
The basic arrangement consists on a thermodynamic cycle that can operate in two modes, charge/discharge, as shown in Figure 2. During the charge cycle, energy is removed from a medium (cold source) and transferred to a medium at a higher temperature (hot source). This is possible by adding energy through a heat pump that consumes electricity. During the discharge cycle, the system operates in the opposite direction, with a different plant layout: energy is removed from the hot source and transferred to the cold source, while producing mechanical energy in a thermal engine.
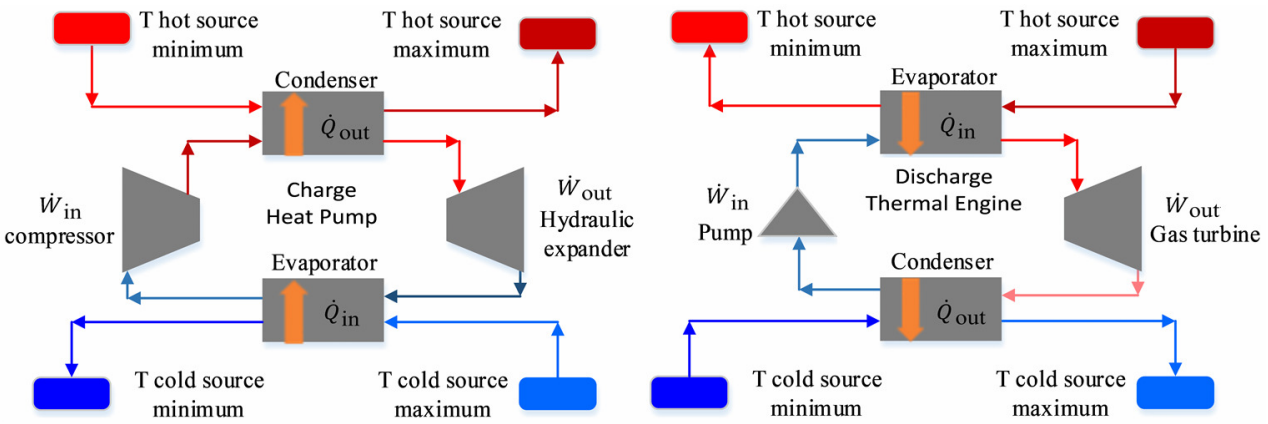

Figure 2. $\mathrm{TCO}_{2}$-TESS charge/discharge processes

Charge and discharge cycles can use different working fluids, but $\mathrm{CO}_{2}$ is adequate for heat and work exchange processes in the temperature range of this application. $\mathrm{CO}_{2}$ is stable throughout the entire temperature range. $\mathrm{CO}_{2}$ can easily reach its supercritical state ( 7.38 bar and $31.1^{\circ} \mathrm{C}$ ) which allows a better temperature profile match to the temperature of the heat source than fluids with an isothermal subcritical evaporation [39]. The $\mathrm{CO}_{2}$ transcritical power cycle allows that thermal integration between cycles and the storage occurs at small temperature difference due to the relatively constant $\mathrm{CO}_{2}$ heat capacity. This way, the compressor outlet temperature can be increased and a greater part of the heat of condensation can be stored at high temperature [27].

Considering the layout proposed in Morandin et al. [27] as a reference, the charge cycle consists of:

- $\mathrm{CO}_{2}$ compression beyond critical point, from a low-pressure level (>40 bar) and sub-ambient temperatures, to high pressure ( $>120$ bar) and moderate temperature $\left(120^{\circ} \mathrm{C}\right)$;

- Heat rejection to hot source;

- Flash or controlled (turbo) expansion to the low-pressure level in the two-phase region;

- Heat absorption from the cold source, until a specific superheated level is reached.

Energy can be transferred until either the cold source has been depleted or the hot source is completely full. The discharge cycle follows:

- Fluid compression from low temperature-low pressure liquid state to a high-pressure level;

- Heat addition from the hot source;

- Fluid expansion in a thermal turbine, obtaining mechanical work;

- De-superheating and condensation with heat rejection to the cold source.

\section{SYSTEM DEFINITION AND LAYOUTS}

This section presents the layouts analysed herein as well as the definition of the global parameters used in the evaluation of performance. The main assumptions are also described. As aforementioned, the layout proposed in Morandin et al. [27] was taken as a reference, and modifications are added to improve the profiles and performances of charge-discharge cycles. 


\section{Thermo-Electric Energy Storage layouts}

Different cycle configurations are analysed herein. The reference cycle is shown in Figure 3 and presented as Layout A. This cycle consists on the combination of a simple HP charge cycle and a simple Thermal Engine (TE) discharge cycle, where two tanks are used on both hot and cold sides. Derived layouts include modifications aimed at decreasing irreversibilities in the charge/discharge processes, decreasing temperature differences between heat exchange streams, and increasing efficiency of the energy storage system. Layout B (Figure 4) includes a sequential expansion and a recuperative layout in the discharge stage. Layout $\mathrm{C}$ (Figure 5) includes reheating and heat storage at different temperature levels and Layout D (Figure 6) adds heat storage at two different temperature levels and an ammonia cycle to improve the charge cycle performance. The ammonia cycle would improve the low temperature operation although additional safety and management measures would be required.
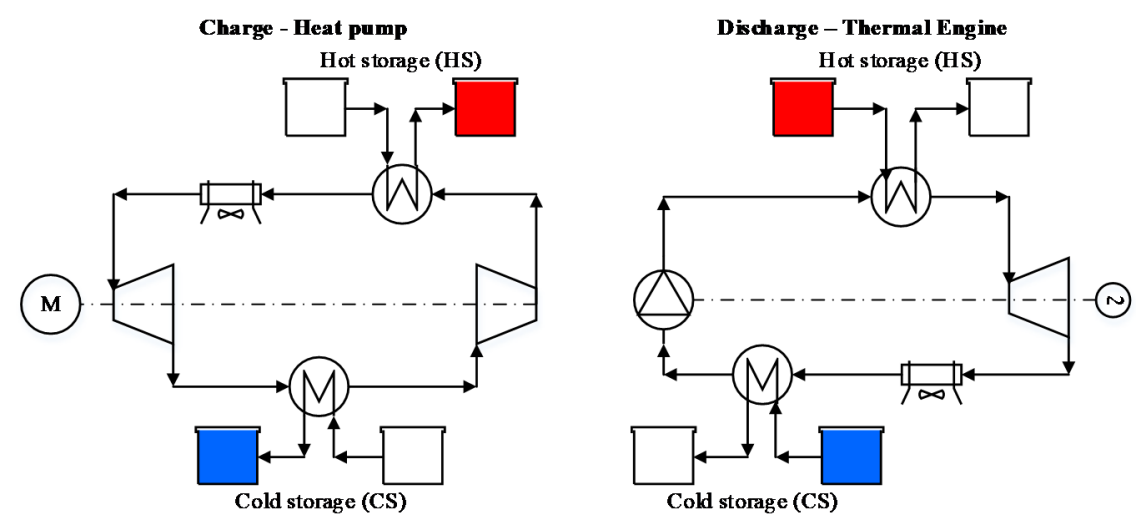

Figure 3. $\mathrm{TCO}_{2}$-TESS Layout A (reference layout)
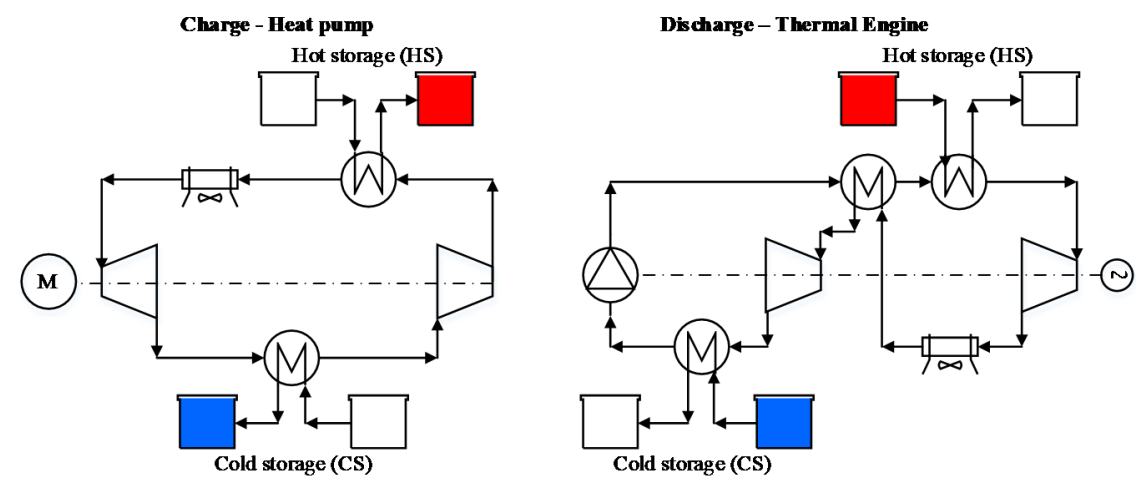

Figure 4. $\mathrm{TCO}_{2}$-TESS Layout $\mathrm{B}$ (reference layout with recuperative cycle during discharge)
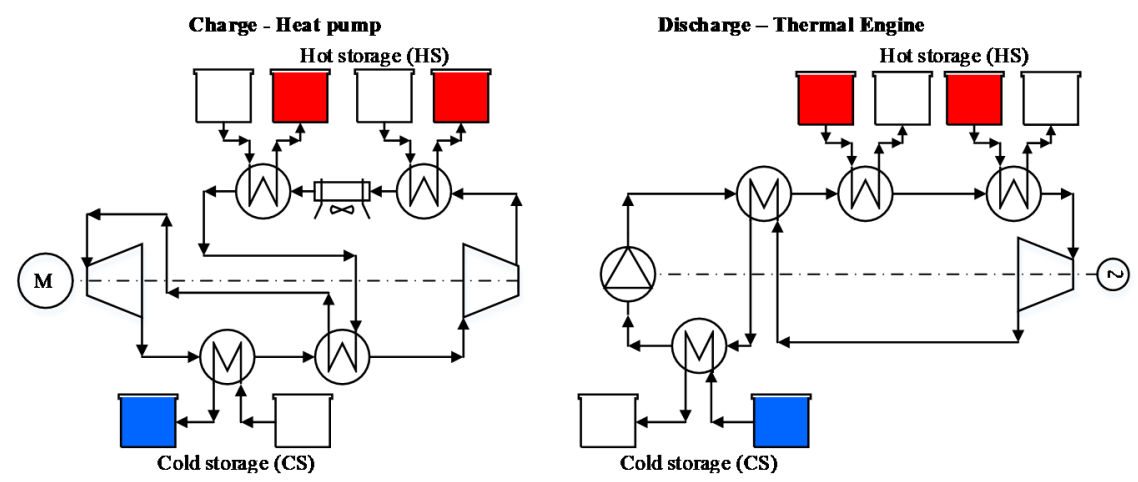

Figure 5. $\mathrm{TCO}_{2}$-TESS Layout $\mathrm{C}$ (reference layout with reheating and heat storage at different temperatures) 

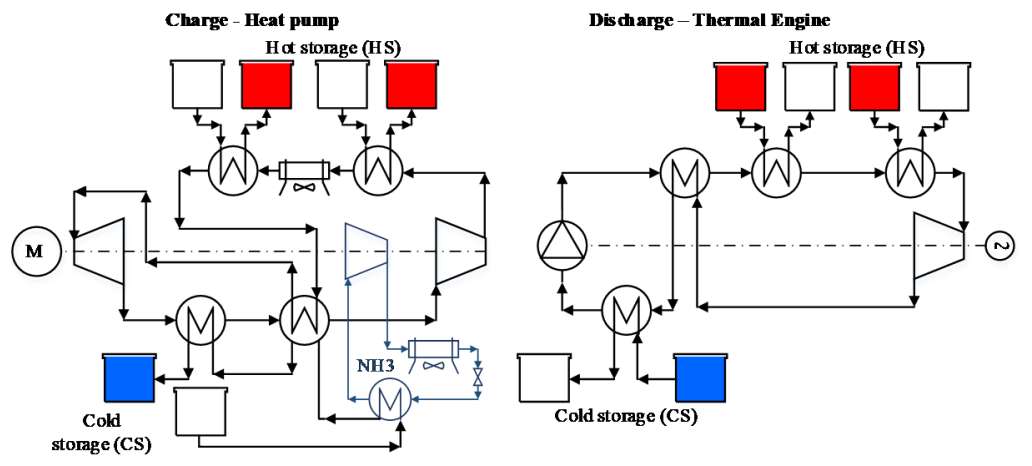

Figure 6. $\mathrm{TCO}_{2}$-TESS Layout $\mathrm{D}$ [reference layout with Ammonia $\left(\mathrm{NH}_{3}\right)$ cycle in the charge cycle and heat storage at different temperatures]

These TEES integrations are studied in detail in section 4.1, in section 4.2, these layouts are extended to accommodate renewable-originated heat (from solar or biomass). This integration, TEES-thermal storage, combines the heat produced in a HP (from electricity) with heat produced by local thermal sources. Therefore a single thermal energy storage system is able to store energy from different sources: electricity (wind, PV) and local thermal renewable resources (solar, geothermal, biomass). Within this context, Figure 7 presents two potential integrations for Layout A: during the charge or discharge processes. Although not graphically represented, the same integration is applied to the remaining layouts.
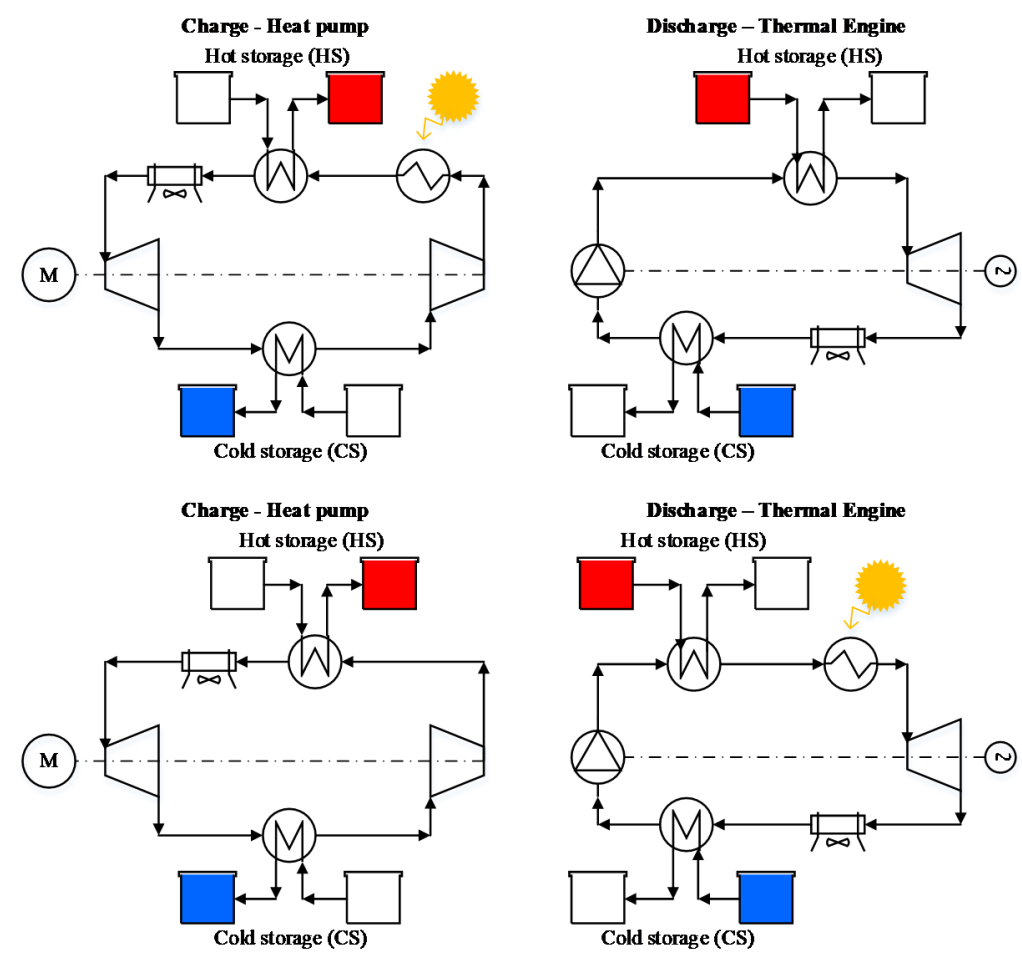

Figure 7. $\mathrm{TCO}_{2}$-TESS reference layout with solar resource support during the charge cycle (top) and during the discharge cycle (bottom)

These integrations can be considered independently or as different strategies to be applied depending on the availability of resources.

\section{Efficiency definitions}

For evaluation of the performance of these cycles the following parameters have been used. 
Round trip efficiency $\left(\eta_{\mathrm{RT}}\right)$ evaluates the ratio between power generated in the thermal engine $\left(\dot{W}_{\mathrm{TE}}\right)$ and power consumption in the heat pump $\left(\dot{W}_{\mathrm{HP}}\right)$ :

$$
\eta_{\mathrm{RT}}=\frac{\dot{W}_{\mathrm{TE}} \times \tau_{\mathrm{D}}}{\dot{W}_{\mathrm{HP}} \times \tau_{\mathrm{C}}}=\frac{\eta_{\mathrm{TE}} \times \dot{Q}_{\text {evap,TE }} \times \tau_{\mathrm{D}}}{\left(1 / C O P_{\mathrm{HP}}\right) \times \dot{Q}_{\text {cond } \mathrm{HP}} \times \tau_{\mathrm{C}}}
$$

where $\tau_{\mathrm{D}}$ is the discharge time, $\tau_{\mathrm{C}}$ is the charge time, $\eta_{\mathrm{TE}}$ is the thermal engine efficiency, $\dot{Q}_{\text {evap,TE }}$ is the heat exchanged in the evaporator in the thermal engine operation, $C O P_{\mathrm{HP}}$ is the heat pump coefficient of performance, and $\dot{Q}_{\text {cond,HP }}$ is the heat exchanged in the condenser in the heat pump operation.

The round trip efficiency is the most relevant parameter for TEES cycles without additional heat. Some of its importance is lost when applied to TEES systems combined with direct thermal heat storage, and then other parameters (discharge cycle efficiency, heat pump coefficient of performance, and round trip efficiency neglecting heat storage losses) must be taken into account.

Discharge cycle efficiency is evaluated by the thermal engine efficiency $\left(\eta_{\mathrm{TE}}\right)$ :

$$
\eta_{\mathrm{TE}}=\frac{\dot{W}_{\mathrm{TE}}}{\dot{Q}_{\mathrm{evap}, \mathrm{TE}}}
$$

Heat pump coefficient of performance $\left(C O P_{\mathrm{HP}}\right)$ :

$$
C O P_{\mathrm{HP}}=\frac{\dot{Q}_{\text {cond,HP }}}{\dot{W}_{\text {comp,HP }}}
$$

Round trip efficiency neglecting heat storage losses $\left(\eta_{\mathrm{RT}}\right)$ :

$$
\eta_{\mathrm{RT}}=\eta_{\mathrm{TE}} \times C O P_{\mathrm{HP}} \times \frac{\tau_{\mathrm{D}}}{\tau_{\mathrm{C}}}
$$

For base Layout $\mathrm{D}$, with the addition of a $\mathrm{NH}_{3}$ cycle, the charge/discharge round trip efficiency $\left(\eta_{\mathrm{RT}}\right)$ is defined considering the additional energy consumption for the $\mathrm{NH}_{3}$ cycle $\left(\dot{W}_{\mathrm{NH}_{3}}\right)$ :

$$
\eta_{\mathrm{RT}}=\frac{\dot{W}_{\mathrm{TE}} \times \tau_{\mathrm{D}}}{\left(\dot{W}_{\mathrm{HP}}+\dot{W}_{\mathrm{NH}_{3}}\right) \times \tau_{\mathrm{C}}}
$$

When additional thermal heat is added, additional relevant information is given by mechanical efficiency $\left(\eta_{\text {mech }}\right)$ defined as:

$$
\eta_{\text {mech }}=\frac{\dot{W}_{\mathrm{TE}} \times \tau_{\mathrm{D}}}{\dot{W}_{\mathrm{HP}} \times \tau_{\mathrm{C}}+\dot{Q}_{\mathrm{RR}} \times\left(\tau_{\mathrm{C}} / \tau_{\mathrm{D}}\right)}
$$

And from the exergy efficiency $\left(\eta_{\mathrm{ex}}\right)$ defined as:

$$
\eta_{\mathrm{ex}}=\frac{\dot{W}_{\mathrm{TE}} \times \tau_{\mathrm{D}}}{E_{\mathrm{x}}^{\mathrm{u}, \mathrm{HP}} \times \tau_{\mathrm{C}}+E_{\mathrm{x}}^{\mathrm{u}, \mathrm{RR}} \times\left(\tau_{\mathrm{C}} / \tau_{\mathrm{D}}\right)}
$$

where the heat exergy is given by: 


$$
E_{\mathrm{x}}^{\mathrm{u}, \text { source }}=\dot{Q} \times\left(1-T_{0} / T_{\text {source }}\right)
$$

where the performance of the cooling and heating system is given by:

$$
\begin{gathered}
\tau_{\mathrm{CS}}=\frac{\dot{Q}_{\text {cond,TE }}}{\dot{Q}_{\text {evap }, \mathrm{HP}}} \\
\tau_{\mathrm{HS}}=\frac{\dot{Q}_{\text {evap,TE }}}{\dot{Q}_{\text {cond,HP }}}
\end{gathered}
$$

where $E_{\mathrm{x}}^{\mathrm{u}, \mathrm{HP}}$ is the exergy of heat from hot source in the charge, $E_{\mathrm{x}}^{\mathrm{u}, \mathrm{RR}}$ is the exergy of the heat obtained from the renewable resource, $T_{0}$ and $T_{\text {source }}$ refer to, respectively, reference temperature and source temperature.

\section{Model assumptions}

The aforementioned layouts were implemented in the Engineering Equation Solver (EES), using lumped models based on the implementation of continuity and energy equations for each subsystem and completed with heat transfer models. Reference for the model structure was based on [15]. Assumptions on the cycle parameters and corresponding variation range were taken from [27,38], presented in Table 1 and Table 2, respectively. These values are extrapolated from commercial axial turbines. For application of this concept, specific equipment for working with transcritical $\mathrm{CO}_{2}$ should be developed.

Table 1. Main assumptions of the cycle

\begin{tabular}{c|c}
\hline Minimum temperature difference & $\Delta T_{\min }=4{ }^{\circ} \mathrm{C}$ \\
Turbine isentropic efficiency (TE) & $\eta_{\mathrm{RT}}=0.88$ \\
Pump isentropic efficiency (TE) & $\eta_{\mathrm{B}}=0.85$ \\
Isentropic efficiency of hydraulic turbine (HP) & $\eta_{\mathrm{TH}}=0.85$ \\
Compressor isentropic efficiency (HP) & $\eta_{\mathrm{C}}=0.86$ \\
$\mathrm{NH}_{3}$ compressor efficiency (3 stages with intercooling) & $\eta_{\mathrm{C}, \mathrm{NH}_{3}}=0.85$ \\
\hline
\end{tabular}

Table 2. Variation range of variables

\begin{tabular}{ccc}
\hline \multicolumn{3}{c}{ Upper and lower limits } \\
\hline HP low pressure $\left(p_{1}\right)$ & {$[\mathrm{bar}]$} & {$[17: 33]$} \\
HP high pressure $\left(p_{3}\right)$ & {$[\mathrm{bar}]$} & {$[100: 200]$} \\
Condenser outlet temperature $\left(T_{3}\right)$ & {$[\mathrm{K}]$} & {$[274: 300]$} \\
TE low pressure $\left(p_{8}\right)$ & {$[\mathrm{bar}]$} & {$[20: 37]$} \\
TE high pressure $\left(p_{7}\right)$ & {$[\mathrm{K}]$} & {$[100: 200]$} \\
Evaporator outlet temperature TE $\left(T_{7}\right)$ & {$[\mathrm{bar}]$} & {$[373: 450]$} \\
$\mathrm{NH}_{3}$ cycle low pressure & {$[\mathrm{bar}]$} & {$[1.5: 3]$} \\
$\mathrm{NH}_{3}$ cycle high pressure & {$[\mathrm{bar}]$} & {$[12: 15]$} \\
\hline
\end{tabular}

\section{RESULTS}

This section presents the main results from the simulation of the different layouts. Firstly, analyses of the layouts without renewable resource support are presented for identification of correct integration and main characteristics of the thermo-electrical energy storage with electrical power input as single source. Secondly, analyses are extended to the integration of additional renewable thermal sources, analysing the effect of combined electrical power/thermal sources. These analyses consider solar thermal 
energy as the renewable source, however, these results can be extended to include biomass waste heat.

\section{Reference layouts without additional renewable heat sources}

Figure 8 shows $T$-s diagrams with the most appropriate value of pressure after simulations [27] obtained for each integration. The HP charge cycle is represented in red, and the discharge cycle with thermal engine is shown in blue. Reference Layout A is presented at the top, followed by Layout $\mathrm{B}$, with reheating before compressor and recuperative layout at expansion, Layout $\mathrm{C}$ with heat storage at two temperature levels, and at the bottom, Layout $\mathrm{D}$ is shown, considering an ammonia cycle.

The global results obtained for these most appropriate values of parameters are presented in Table 3. The results for extensive magnitudes are expressed in terms of $1 \mathrm{~kg} \mathrm{CO} 2$ circulating in the cycle, making the analysis non-dependent of global system size at this conceptual preliminary stage.

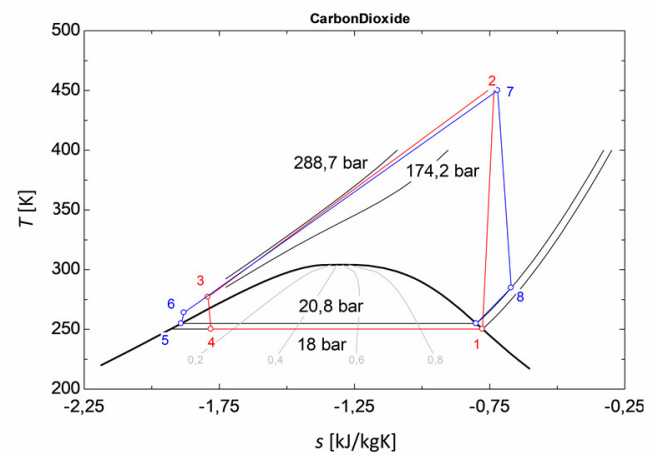

(a)

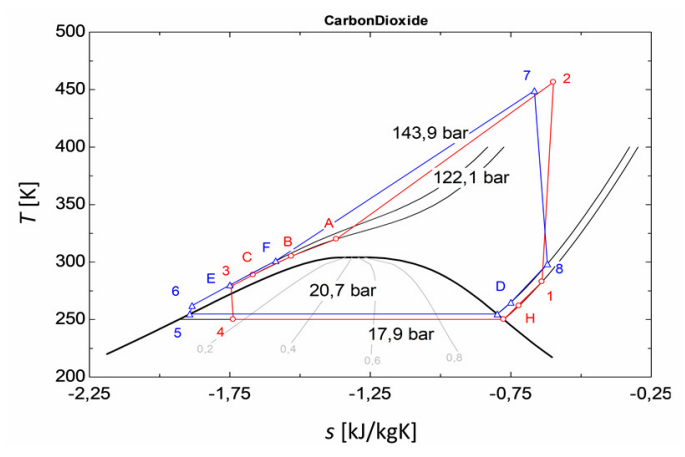

(b)

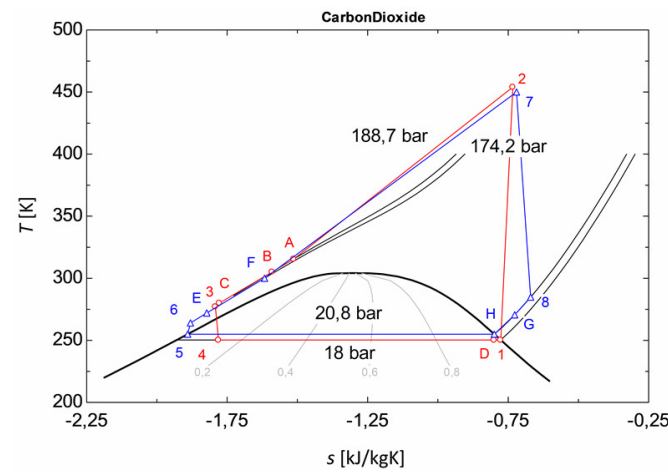

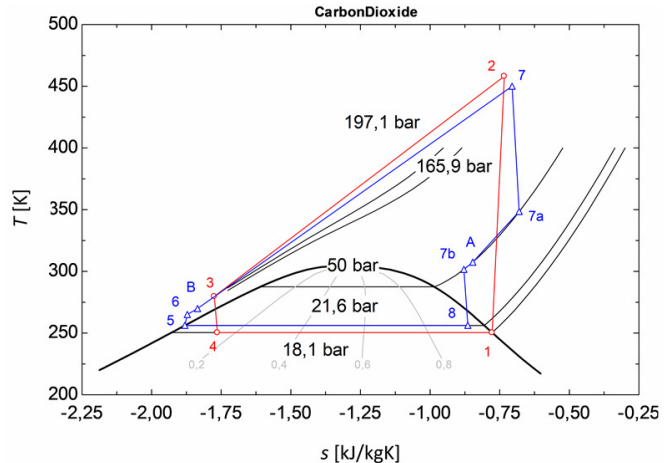

(c)

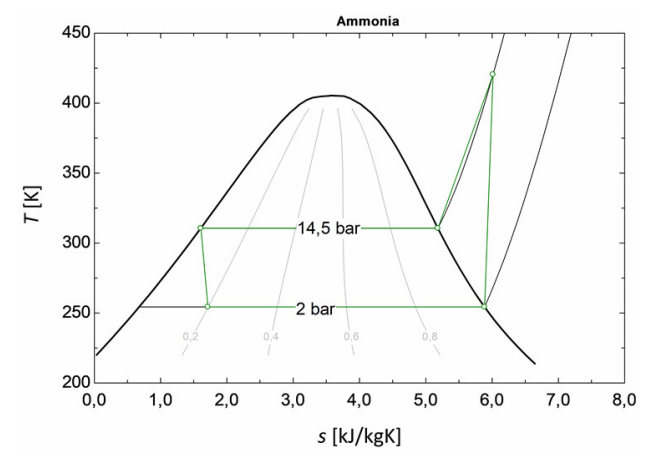

d)

Figure 8. T-s diagrams - Layout A: reference layout (a); Layout B: recuperative cycle in discharge (b); Layout C: partial expansion (c); Layout D: with ammonia cycle $\mathrm{NH}_{3}$ (d); $\mathrm{HP}$ (red),

$\mathrm{TE}$ (blue), $\mathrm{NH}_{3}$ (green) 
Analysis of Table 3 reveals how round-trip efficiency increased by $3 \%$ with the addition of the $\mathrm{NH}_{3}$ cycle compared to the reference layout. This is due to the smaller charge/discharge ratio, even though the addition of a $\mathrm{NH}_{3}$ cycle (as the small ratio between $\mathrm{CO}_{2}$ and $\mathrm{NH}_{3}$ masses) results in a smaller increase in the total consumption that is not compensated by the additional power obtained with the extra expansion. Layout D has no surplus energy due to the additional adjustment between $\mathrm{NH}_{3}$ mass flow and charging hours. With additional heat exchangers and heat storage at two temperature levels on the hot side, the energy at the condenser is affected because only a fraction of the condensed energy of the HP is stored (COP of the heat pump decreases). In an opposite direction, the thermal engine efficiency is increased due to waste heat recuperation from turbine exhaust, thus reducing the contribution from storage. In Layout A, a relatively simple layout, the charging hours must be increased by $9.3 \%$ to achieve sufficient energy on the cold side and surplus energy on the hot side. For Layout A, global round trip efficiency $\eta_{\mathrm{RT}}$ is $56.47 \%$. Layout D presents better energy integration, without surplus energy on the hot side, with a higher round trip efficiency, $59.6 \%$. Layout D presents a more complex integration, which would probably not be considered in smaller plants or residential applications. Compared with Layout D, Layout C presents good energy integration with relatively low energy surplus on the hot side $(0.9 \%)$ and the best round trip efficiency within the analysed layouts, $61.37 \%$. Layout B, recuperative cycle with double expansion, presented higher complexity, and its best solution yielded a relatively lower round trip efficiency $\left(\eta_{\mathrm{RT}}=57.96 \%\right)$ than Layout $\mathrm{C}$, with $0.1 \%$ surplus energy.

Table 3. Best values of parameters for TEES without renewable resources

\begin{tabular}{cccccc}
\hline & & Layout A & Layout B & Layout C & Layout D \\
\hline & $\dot{Q}_{\mathrm{HS} ; \mathrm{HP} ; \mathrm{A}}$ & 373.3 & 370.8 & 324.4 & 343.4 \\
Heat & $\dot{Q}_{\mathrm{HS} ; \mathrm{TE} ; \mathrm{A}}$ & 398.9 & 390.5 & 376.8 & 383.1 \\
{$\left[\mathrm{~kW} / \mathrm{kg} \mathrm{CO} \mathrm{CO}_{2}\right]$} & $\dot{Q}_{\mathrm{CS} ; \mathrm{HP} ; \mathrm{A}}$ & 251.5 & 247.1 & 254.8 & 1,306 \\
& $\dot{Q}_{\mathrm{CS} ; \mathrm{TE} ; \mathrm{A}}$ & 313.2 & 260.4 & 291.4 & 297.4 \\
\hline & $\dot{W}_{\mathrm{C} ; \mathrm{A}}$ & 137.6 & 140.6 & 130.6 & 137.6 \\
Electric power & $\dot{W}_{\mathrm{TH} ; \mathrm{A}}$ & 15.72 & 16.8 & 11.07 & 15.72 \\
consumed/generated & $\dot{W}_{\mathrm{B} ; \mathrm{A}}$ & 17.39 & 16.46 & 13.99 & 17.39 \\
[kW/kg CO 2$]$ & $\dot{W}_{\mathrm{T} ; \mathrm{A}}$ & 103.1 & 92.08 & 99.39 & $103.1+349.9$ \\
\hline Charge/discharge & $h_{\mathrm{CS} ; \mathrm{A}}$ & 1.068 & 1.053 & 1.164 & 1.116 \\
hours ratio [-] & $h_{\mathrm{HS} ; \mathrm{A}}$ & 1.245 & 1.054 & 1.144 & 1.115 \\
\hline Charge/discharge & $E_{\mathrm{excess} ; \mathrm{A}}$ & 1.093 & 1.001 & 1.009 & 1 \\
energy ratio [-] & $C O P_{\mathrm{HP} ; \mathrm{A}}[-]$ & 3.064 & 2.996 & 2.713 & 2.818 \\
\hline & $\eta_{\mathrm{TE} ; \mathrm{A}}[\%]$ & 21.48 & 19.36 & 22.37 & 22.37 \\
Efficiency & $\eta_{\mathrm{RT} ; \mathrm{A}}[\%]$ & 56.47 & 57.96 & 61.37 & 59.6 \\
\hline
\end{tabular}

\section{Thermoelectric Energy Storage with thermal heat from renewable sources}

This section extends analyses for the integration of a renewable heat source, combining simultaneous energy storage from electrical and thermal sources. A single storage system is able to store power and heat. This storage concept can be applied to different power ranges, from residential applications to power plants, for surplus solar thermal heat and electricity (i.e., excess nocturnal wind production in some periods). The effect of the additional heat on the previous cases increases the discharging capacity and also the charge/discharge time ratio. Figure 9 presents the $T-s$ diagrams for Layout A (single expansion with solar energy) and Layout $\mathrm{C}$ (sequential expansion with solar energy). 

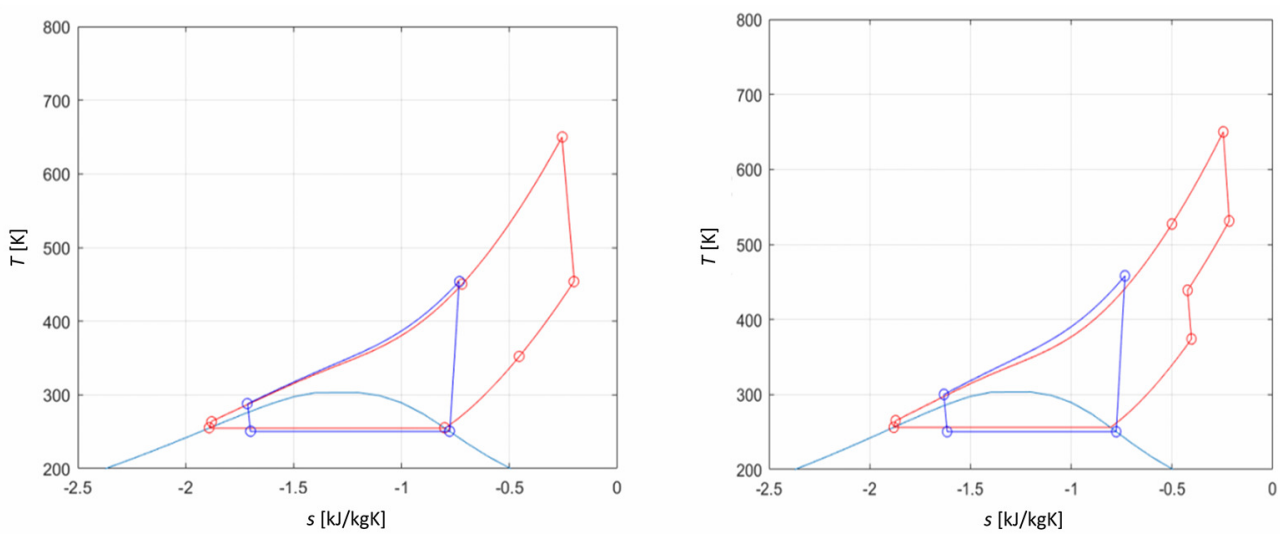

Figure 9. T-s diagrams for Layout A, single expansion with solar (left), and Layout C, sequential expansion with solar (right)

The temperature range for solar applications considered herein is $200-800{ }^{\circ} \mathrm{C}$, and analyses carried out for Turbine Inlet Temperatures (TIT) between $450 \mathrm{~K}$ and 1,000 K (without and with solar contribution, respectively). Figure 10a presents Turbine Exhaust Temperatures (TET) and power as a function of TIT, for a fixed expansion ratio in Layout A. An increase in the expansion ratio is required to avoid excessively high temperatures at the condenser, increasing the required stored energy and charging time Figure $10 \mathrm{~b}$.

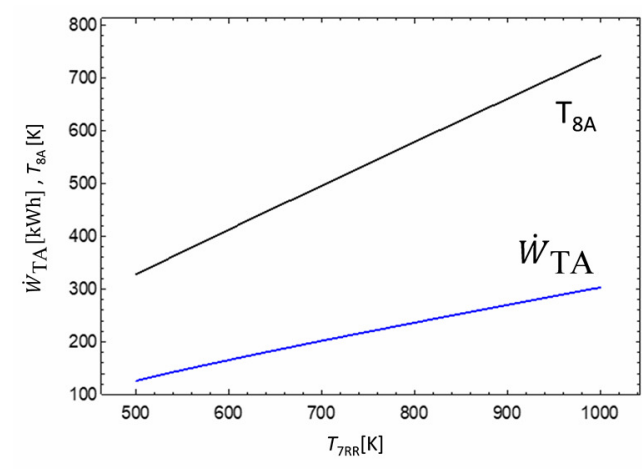

(a)

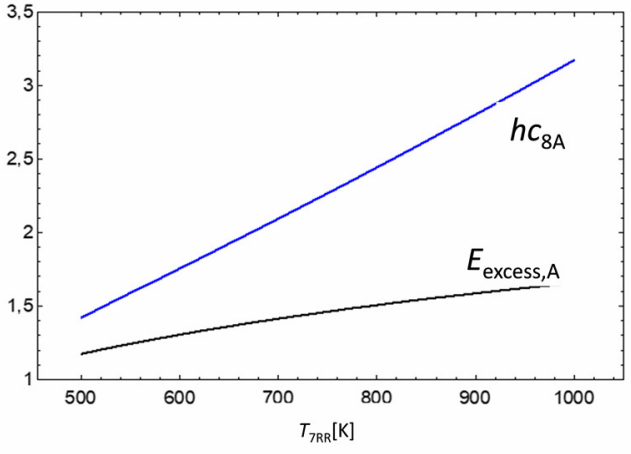

(b)

Figure 10. Effect of TIT during the discharge cycle [work and exhaust temperatures (left) and surplus energy and charging hours (right)]

The charge/discharge ratio affects the remaining variables of the cycle. When only the low pressure varies, low pressure during charge must also vary to maintain reasonable differences between evaporation during charge and condensation during discharge. In this case, the energy stored depends only on charging time, which is directly proportional to the turbine outlet temperature, as more time will be spent to evacuate heat in the condenser of the thermal engine.

The following figures show the effect of pressure variation in the cycles with renewable resource support, distinguishing between integration during charge and during discharge. Two adjustments were considered: modification of the discharge cycle only, maintaining the charge cycle parameters obtained from previous analyses, and modification of both charge/discharge cycles, maintaining the best value of ratios obtained previously.

Due to mechanical constraints, the maximum pressure was limited to $300 \mathrm{bar}$, the maximum expansion ratio was limited to 15 , resulting in a cold focus temperature of $10{ }^{\circ} \mathrm{C}$. This temperature is suitable for cool storage, even in hot climates with high solar resource availability. 
Figure 11 shows the effect of modifying the discharge expansion ratio on the system performance, under these assumptions of Layout A. The analysis includes Renewable Resources (RR) during charge and discharge cycles, and two options for charge/discharge cycles: modification of discharge cycle $\left(R_{\exp }\right)$ only, and modification of discharge cycle $\left(R_{\exp }\right)$ according to the pressure ratio during the charge cycle $\left(R_{\text {com }}\right)$. It is suggested to improve the evolution of charge/discharge temperature profiles.

From Figure 11 it can be observed that when renewable resource is applied during the charge cycle, exergy efficiency is clearly increased. A higher increase in turbine power is obtained than with the useful heat obtained from variation of pressure ratios during charge and discharge. However, if renewable heat is applied to the discharge cycle, better global parameter values are obtained when only the discharge process is modified. With variable pressure ratios, higher mechanical efficiencies can be reached. When varying pressure and expansion ratios during charge/discharge, energy consumption is increased during the charge cycle. However, the increase in the compressor outlet temperature causes a greater reduction in thermal energy demand than the increase in energy consumption during the charge cycle. Regarding constant temperature, supply of thermal energy is increased. The effect of expansion ratio on surplus energy can be verified in Figure 11d. Round trip efficiency, which only evaluates electrical power, is reduced by the charge/discharge adjustment with variable expansion and pressure ratios. However, the round trip efficiency increases if the charge cycle is not modified.

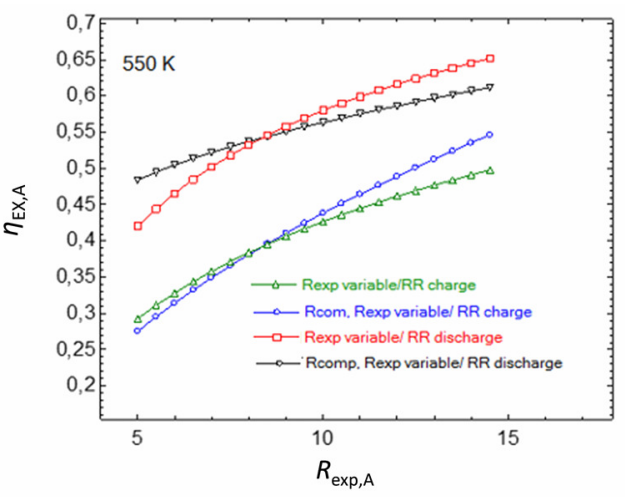

(a)

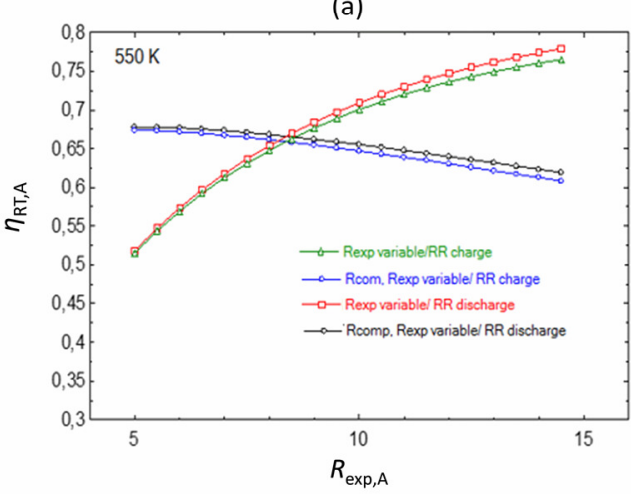

(c)

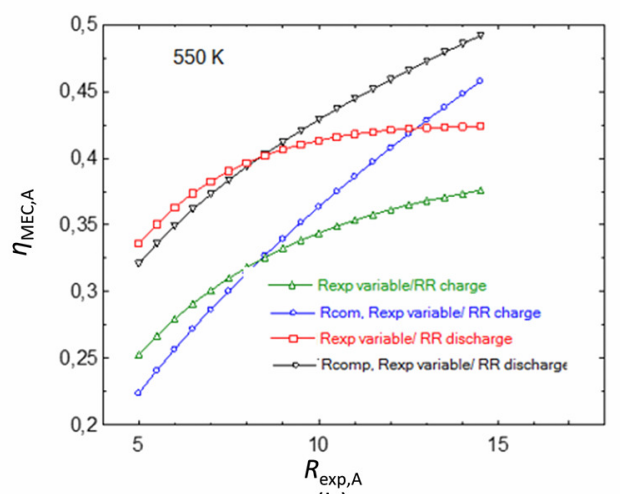

(b)

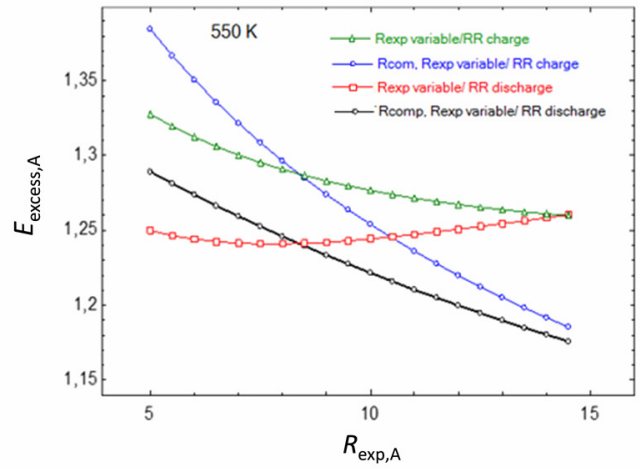

(d)

Figure 11. Layout A - TIT $550 \mathrm{~K}$ : exergy efficiency (a); mechanical efficiency (b); round trip efficiency (c); surplus energy (d) as a function of expansion ratio

Table 4 presents the main parameters for the best operation performance at $550 \mathrm{~K}$ and $950 \mathrm{~K}$.

With additional thermal energy, although the importance of the round trip efficiency is decreased, values as high as 0.94 are obtained. This evidences how modifications in charge/discharge cycles maximize the remaining parameters. When the heat source is applied to the discharge cycle, the adjustment of both cycles penalizes exergy efficiency 
but increases mechanical efficiency, meanwhile surplus energy and charging time are reduced. Figure 12 presents analyses for Layout D, with additional heat supply.

Table 4. Layout A - best obtained results with renewable resource (TIT $550 \mathrm{~K}$ and $950 \mathrm{~K}$ )

\begin{tabular}{|c|c|c|c|c|c|c|c|c|}
\hline \multicolumn{9}{|c|}{ Renewable resource during charge } \\
\hline $\begin{array}{l}\text { Modified } \\
\text { parameter }\end{array}$ & $T_{\mathrm{FC} ; \mathrm{A}}$ & $R_{\exp }$ Opt. & $R_{\text {com }}$ & $\eta_{\mathrm{ex} ; \mathrm{A}}$ & $\eta_{\text {mech;A }}$ & $\eta_{\mathrm{RT} ; \mathrm{A}}$ & $E_{\text {excess;A }}$ & $h_{\mathrm{CS} ; \mathrm{A}}$ \\
\hline$P_{7}$ & \multirow{2}{*}{$550 \mathrm{~K}$} & 14.5 & 10.48 & 0.4977 & 0.3757 & 0.7651 & 1.26 & 1.379 \\
\hline$P_{7}$ and $P_{2}$ & & 14.5 & 18.15 & 0.5463 & 0.4575 & 0.6081 & 1.185 & 1.326 \\
\hline$P_{7}$ & \multirow{2}{*}{$950 \mathrm{~K}$} & 14.5 & 10.48 & 0.1847 & 0.1552 & 0.9449 & 2.014 & 2.693 \\
\hline$P_{7}$ and $P_{2}$ & & 14.5 & 18.15 & 0.1931 & 0.1648 & 0.751 & 1.944 & 2.589 \\
\hline \multicolumn{9}{|c|}{ Renewable resource during discharge } \\
\hline $\begin{array}{l}\text { Modified } \\
\text { parameter }\end{array}$ & $T_{\mathrm{FC} ; \mathrm{A}}$ & $R_{\text {exp }}$ Opt. & $R_{\text {com }}$ & $\eta_{\mathrm{ex} ; \mathrm{A}}$ & $\eta_{\text {mech;A }}$ & $\eta_{\mathrm{RT} ; \mathrm{A}}$ & $E_{\text {excess;A }}$ & $h_{\mathrm{CS} ; \mathrm{A}}$ \\
\hline \multirow{2}{*}{$\begin{array}{c}P_{7} \\
P_{7} \text { and } P_{2}\end{array}$} & \multirow{2}{*}{$550 \mathrm{~K}$} & 14.5 & 10.48 & 0.6521 & 0.4238 & 0.779 & 1.26 & 1.413 \\
\hline & & 14.5 & 18.15 & 0.6118 & 0.4918 & 0.6192 & 1.176 & 1.358 \\
\hline \multirow{2}{*}{$\begin{array}{c}P_{7} \\
P_{7} \text { and } P_{2}\end{array}$} & \multirow{2}{*}{$950 \mathrm{~K}$} & 14.5 & 10.48 & 0.4251 & 0.3181 & 0.954 & 1.653 & 2.729 \\
\hline & & 14.5 & 18.15 & 0.4001 & 0.3189 & 0.7514 & 1.6 & 2.623 \\
\hline
\end{tabular}

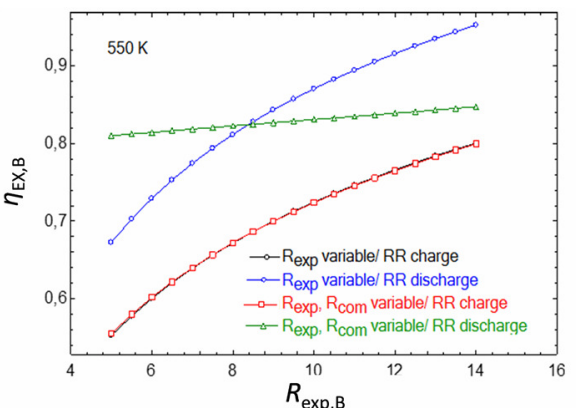

(a)

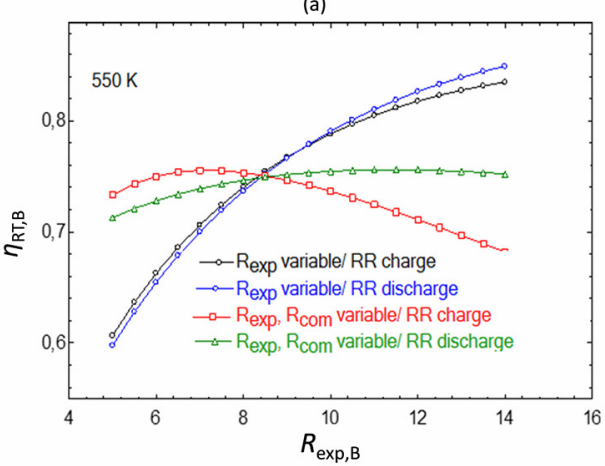

(c)

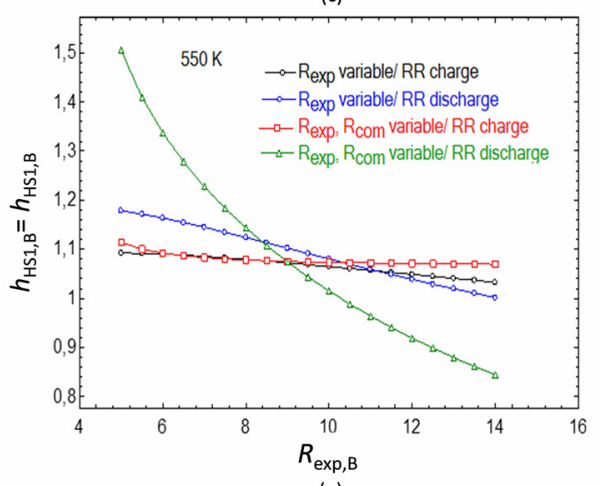

(e)

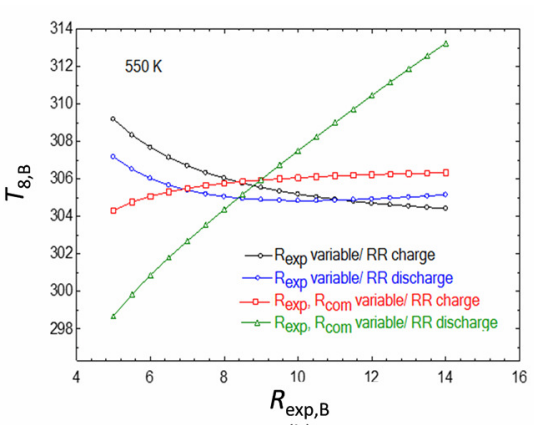

(b)

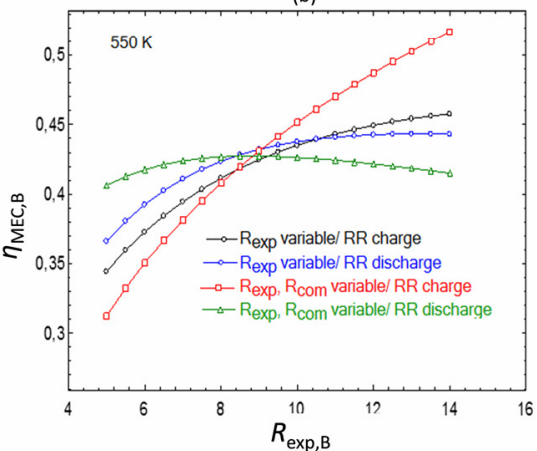

(d)

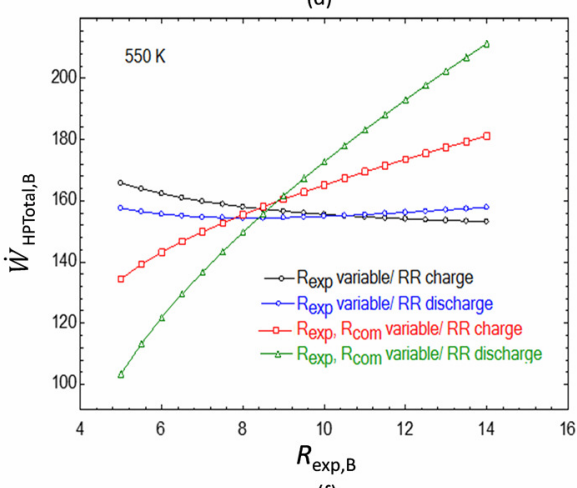

(f)

Figure 12. Layout D - TIT $550 \mathrm{~K}$ : exergy efficiency (a); temperature in B (b); round trip efficiency (c); mechanical efficiency (d); charging time (e); heat pump power consumption (f) as a function of expansion ratio 
As in the previous case, exergy efficiency increases along with the expansion ratio, because of a higher increase in the expansion work. Air fan systems control temperature in $\mathrm{B}$, evacuating excess heat. Figure $12 \mathrm{~b}$ presents the effects of regulating temperature in $\mathrm{B}$. The charge/discharge time ratio is set by the hot side constraints, as in the cold side the ammonia cycle compensates any energy unbalance. Variations can be analysed as a function of energy charge and charging time, a combination required by the $\mathrm{CO}_{2}$ and $\mathrm{NH}_{3}$ cycles. Energy charge increases with pressure ratio, more pronouncedly with RR during the charge cycle (increased $\mathrm{NH}_{3}$ mass flow). When the heat source is applied to the discharge $\mathrm{CO}_{2}$ cycle, consumption increases more in comparison with consumption decrease in the $\mathrm{NH}_{3}$ cycle. When only the discharge cycle is modified, energy consumption depends on the charging time. This is directly reflected on the round trip efficiency, as shown by Figure 12c, which increases along with the expansion ratio for a fixed charge cycle. When varying charge and discharge with RR during charge, initially the round trip efficiency increases but then decreases. With RR during discharge, the increase in consumption is compensated by the reduced charging time. In the other cases, total consumption is almost constant and the output energy during discharge is increased. The charge/discharge time ratio is almost constant. This cycle has zero energy excess because of the adjustment between the charge cycles. Table 5 presents main global parameters for best operation performance at $550 \mathrm{~K}$ and $950 \mathrm{~K}$.

Table 5. Layout $\mathrm{D}$ - best values of parameters with RR, for TIT $550 \mathrm{~K}$ and $950 \mathrm{~K}$

\begin{tabular}{|c|c|c|c|c|c|c|c|c|c|}
\hline \multicolumn{10}{|c|}{ Renewable resource during charge } \\
\hline $\begin{array}{l}\text { Modified } \\
\text { parameter }\end{array}$ & $T_{\mathrm{FC} ; \mathrm{B}}$ & $R_{\exp }$ Opt. & $R_{\text {com }}$ & $\eta_{\mathrm{ex} ; \mathrm{B}}$ & $\eta_{\text {mech;B }}$ & $\eta_{\mathrm{RT} ; \mathrm{B}}$ & $E_{\text {excess } ; \mathrm{B}}$ & $h_{\mathrm{HS} ; \mathrm{B}}$ & $X_{\mathrm{NH}_{3} ; \mathrm{B}}$ \\
\hline$P_{7}$ & & 14.5 & 10.49 & 0.8085 & 0.4591 & 0.8377 & 1 & 1.029 & 0.08912 \\
\hline$P_{7}$ and $P_{2}$ & $500 \mathrm{~K}$ & 14.5 & 18.15 & 0.8072 & 0.5241 & 0.6745 & 1 & 1.096 & 0.06703 \\
\hline$P_{7}$ & $050 \mathrm{~K}$ & 14.5 & 10.49 & 0.5278 & 0.3447 & 1.172 & 1 & 1.033 & 0.3897 \\
\hline$P_{7}$ and $P_{2}$ & $950 \mathrm{n}$ & 14.5 & 18.15 & 0.5294 & 0.3537 & 1.037 & 1 & 1.027 & 0.3833 \\
\hline \multicolumn{10}{|c|}{ Renewable resource during discharge } \\
\hline $\begin{array}{l}\text { Modified } \\
\text { parameter }\end{array}$ & $T_{\mathrm{FC} ; \mathrm{B}}$ & $R_{\exp }$ Opt. & $R_{\text {com }}$ & $\eta_{\mathrm{ex} ; \mathrm{B}}$ & $\eta_{\text {mech;B }}$ & $\eta_{\mathrm{RT} ; \mathrm{B}}$ & $E_{\text {excess;B }}$ & $h_{\mathrm{CS} ; \mathrm{B}}$ & $X_{\mathrm{NH}_{3} ; \mathrm{B}}$ \\
\hline \multirow{2}{*}{$\begin{array}{c}P_{7} \\
P_{7} \text { and } P_{2}\end{array}$} & \multirow{2}{*}{$550 \mathrm{~K}$} & 14.5 & 10.49 & 0.9613 & 0.4427 & 0.8534 & 1 & 0.993 & 0.1038 \\
\hline & & 14.5 & 18.15 & 0.8495 & 0.4134 & 0.7588 & 1 & 0.8278 & 0.1607 \\
\hline \multirow{2}{*}{$\begin{array}{c}P_{7} \\
P_{7} \text { and } P_{2}\end{array}$} & \multirow{2}{*}{$950 \mathrm{~K}$} & 14.5 & 10.49 & 0.6193 & 0.3404 & 1.18 & 1 & 0.993 & 0.4118 \\
\hline & & 14.5 & 18.15 & 0.5952 & 0.3327 & 1.092 & 1 & 0.8278 & 0.5376 \\
\hline
\end{tabular}

When only the discharge cycle is modified, round trip efficiency is increased as compressor power is not affected. Turbine work is increased. With RR during discharge, mechanical and exergy efficiencies are increased but differences are reduced at higher temperatures. When both charge and discharge cycles are modified, mechanical efficiency is increased but differences are small. For Layout D with RR during discharge, charging time can be lower than discharging time.

Figure 13 presents the effects of expansion ratio variations for Layout $\mathrm{C}$.

Mechanical efficiency, combining both power and heat sources, is significantly increased when charge and discharge cycles are modified. The increase in power consumption during charge is fully compensated by the decrease in additional heat supply. Round trip efficiency follows the same trend than reference Layout A. As in previous cases, for higher expansion ratios, the charging time is reduced because of the lower temperature of turbine exhaust. Lower charge/discharge time ratios are achieved, due to the decrease in $T_{3}$. This reduces quality at the turbine exhaust, increasing the available latent heat at evaporator. There is less surplus energy when both charge and discharge cycles are modified. 


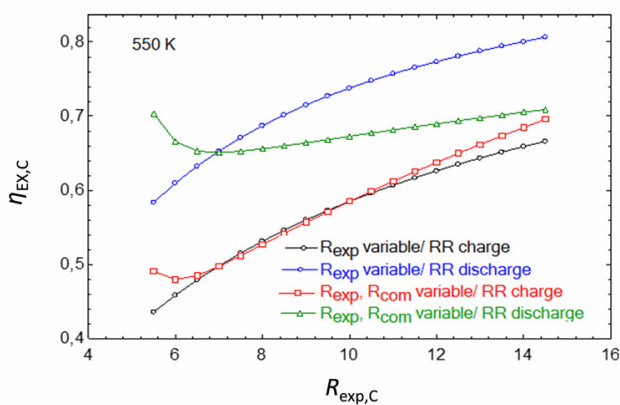

(a)

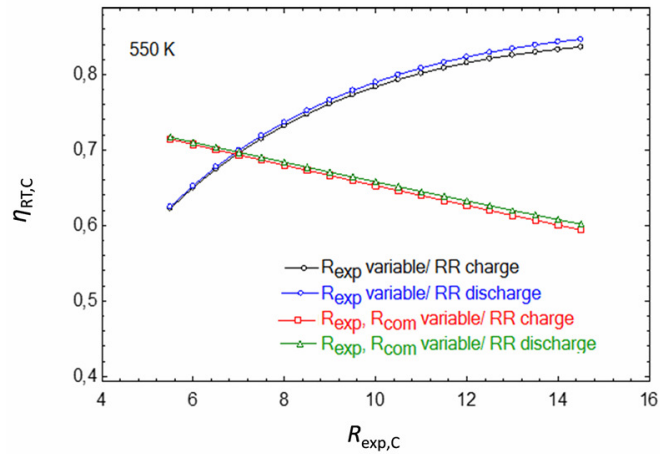

(c)

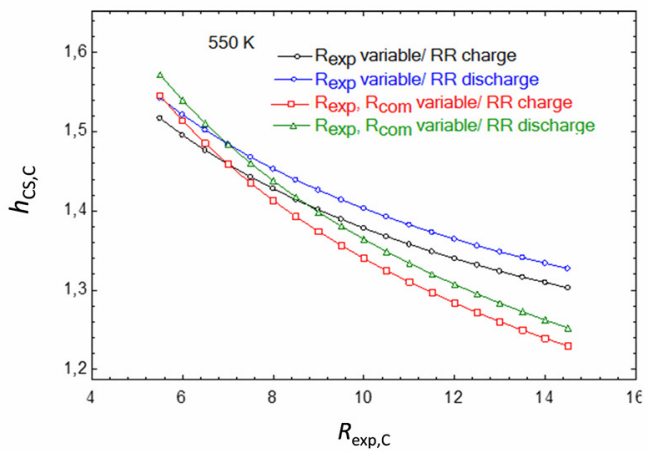

(e)

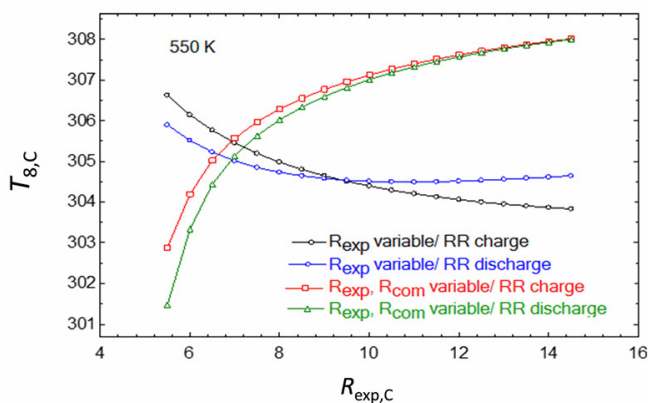

(b)

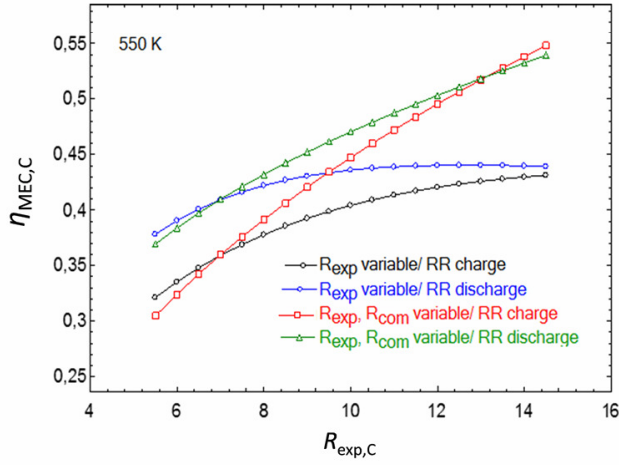

(d)

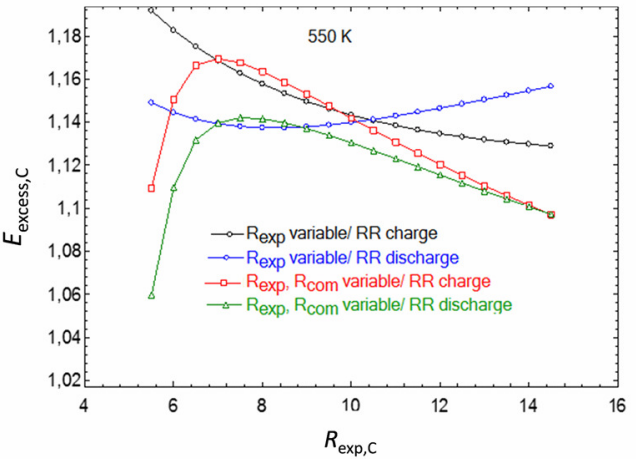

(f)

Figure 13. Layout C - TIT $550 \mathrm{~K}$ : exergy efficiency (a); temperature in B (b); round trip efficiency (c); mechanical efficiency (d); charging time (e); surplus energy (f) as a function of expansion ratio

Figure 14 presents exergy and round trip efficiencies for Layout C, at TIT $950 \mathrm{~K}$. At higher temperatures, trends are similar, but differences between the alternative options are reduced due to the greater share of thermal heat stored.

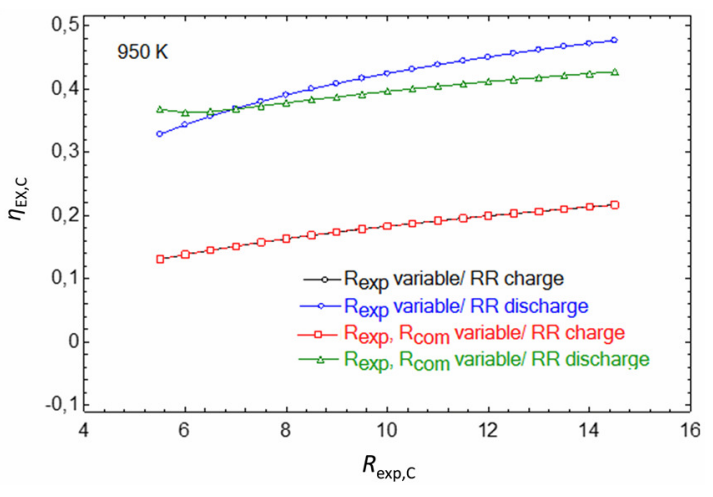

(a)

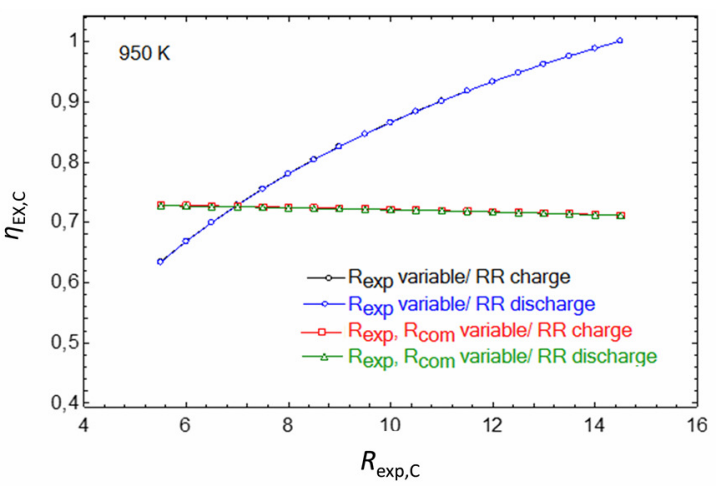

(b)

Figure 14. Layout C - TIT $950 \mathrm{~K}$ : exergy efficiency (a) and round trip efficiency (b) 
At low pressures, the increase in exergy efficiency is not as significant as in TIT $550 \mathrm{~K}$, where higher efficiencies were achieved at higher expansion ratios. The decrease in surplus energy at higher expansion ratios was smaller. Table 6 presents main global parameters for best operation performance at $550 \mathrm{~K}$ and $950 \mathrm{~K}$.

Table 6. Layout $\mathrm{C}$ - best values of parameters for TIT at $550 \mathrm{~K}$ and $950 \mathrm{~K}$

\begin{tabular}{|c|c|c|c|c|c|c|c|c|}
\hline \multicolumn{9}{|c|}{ Renewable resource during charge } \\
\hline $\begin{array}{l}\text { Modified } \\
\text { parameter }\end{array}$ & $T_{\mathrm{FC} ; \mathrm{C}}$ & $R_{\exp }$ Opt. & $R_{\text {com }}$ & $\eta_{\mathrm{ex} ; \mathrm{C}}$ & $\eta_{\text {mech;C }}$ & $\eta_{\mathrm{RT} ; \mathrm{C}}$ & $E_{\text {excess;C }}$ & $h_{\mathrm{CS} ; \mathrm{C}}$ \\
\hline $\begin{array}{c}P_{7} \\
P_{7} \text { and } P_{2}\end{array}$ & $550 \mathrm{~K}$ & $\begin{array}{l}14.5 \\
14.5\end{array}$ & $\begin{array}{c}6.82 \\
14.23\end{array}$ & $\begin{array}{l}0.6659 \\
0.6957\end{array}$ & $\begin{array}{l}0.4311 \\
0.5481\end{array}$ & $\begin{array}{l}0.8359 \\
0.5942\end{array}$ & $\begin{array}{l}1.129 \\
1.097\end{array}$ & $\begin{array}{l}1.304 \\
1.229\end{array}$ \\
\hline $\begin{array}{c}P_{7} \\
P_{7} \text { and } P_{2}\end{array}$ & $950 \mathrm{~K}$ & $\begin{array}{l}14.5 \\
14.5 \\
\end{array}$ & $\begin{array}{c}6.82 \\
14.23 \\
\end{array}$ & $\begin{array}{l}0.2167 \\
0.2229 \\
\end{array}$ & $\begin{array}{c}0.1679 \\
0.182 \\
\end{array}$ & $\begin{array}{c}1.00 \\
0.7121 \\
\end{array}$ & $\begin{array}{l}1.863 \\
1.809 \\
\end{array}$ & $\begin{array}{r}2.60 \\
2.452 \\
\end{array}$ \\
\hline \multicolumn{9}{|c|}{ Renewable resource during discharge } \\
\hline $\begin{array}{l}\text { Modified } \\
\text { parameter }\end{array}$ & $T_{\mathrm{FC} ; \mathrm{C}}$ & $R_{\exp }$ Opt. & $R_{\text {com }}$ & $\eta_{\mathrm{ex} ; \mathrm{C}}$ & $\eta_{\text {mech;C }}$ & $\eta_{\mathrm{RT} ; \mathrm{C}}$ & $E_{\text {excess } ; \mathrm{C}}$ & $h_{\mathrm{CS} ; \mathrm{C}}$ \\
\hline $\begin{array}{c}P_{7} \\
P_{7} \text { and } P_{2}\end{array}$ & $550 \mathrm{~K}$ & $\begin{array}{l}14.5 \\
14.5\end{array}$ & $\begin{array}{c}6.82 \\
14.23 \\
\end{array}$ & $\begin{array}{l}0.8065 \\
0.7066\end{array}$ & $\begin{array}{l}0.4391 \\
0.5391\end{array}$ & $\begin{array}{l}0.8461 \\
0.6015 \\
\end{array}$ & $\begin{array}{l}1.157 \\
1.107\end{array}$ & $\begin{array}{l}1.327 \\
1.252\end{array}$ \\
\hline $\begin{array}{c}P_{7} \\
P_{7} \text { and } P_{2}\end{array}$ & $950 \mathrm{~K}$ & $\begin{array}{l}14.5 \\
14.5\end{array}$ & $\begin{array}{c}6.82 \\
14.23\end{array}$ & $\begin{array}{l}0.4765 \\
0.4271\end{array}$ & $\begin{array}{l}0.3235 \\
0.3213\end{array}$ & $\begin{array}{c}1.00 \\
0.7118\end{array}$ & $\begin{array}{c}1.53 \\
1.527\end{array}$ & $\begin{array}{l}2.626 \\
2.478\end{array}$ \\
\hline
\end{tabular}

For high temperatures and renewable resource in the discharge cycle, variations in the charge cycle do not affect significantly the main parameters. However, the best obtained pressure ratio after simulations almost doubles, increasing the requirements of the compressor. For renewable resource in the charge cycle, the improvements of modifying both charge and discharge cycles are clearer.

\section{Comparison of systems}

The analysed layouts presented differences in constructive configuration and parameters. For reference Layout A, when charge and discharge cycles were modified complementarily, a clear improvement of global parameters was obtained. Achievement of the same power output in with unaltered charge cycle, more heat supply is required (obtained externally from heat exchangers and/or storage). Best result of modification of the charge cycle requires a pressure ratio increase of $73 \%$. For high temperatures, cycle A is the best option with complementary charge/discharge variations.

Layout D presents a more complex integration but enables the obtainment of parameter values that were not possible with the other configurations. The addition of the ammonia cycle enables additional adjustments for energy storage, allowing energy to be balanced in any operation condition. However, with Layout D no clear advantage was obtained when renewable thermal energy was added and cycles were adapted by varying charge and discharge cycles simultaneously. This resulted in a higher pressure ratio, up to 18.

Regarding Layout C, intermediate results between Layouts A and D were obtained. With a single heat pump cycle, the layout was simpler than Layout B. Higher energy integration than in Layout $\mathrm{A}$ was obtained with the addition of heat exchangers and heat storage at two temperatures. For Layout $\mathrm{C}$, there were no relevant differences when the charge cycle was modified, even at high temperatures.

Selection of one layout for a specific application will depend on investment costs and complexity. Possibilities for energy systems evolve from A to $\mathrm{D}$, with $\mathrm{C}$ being an intermediate option. Depending on the type of application (i.e., power plant or residential), a specific layout is selected. Layouts $\mathrm{D}$ and $\mathrm{C}$ provide the best global parameters. Regarding the operation temperatures, those between $550 \mathrm{~K}$ and $750 \mathrm{~K}$ with 
simultaneous variation of both charge/discharge cycles provide better results. With higher temperatures, 750-950 K, modification of the charge cycle in Layouts D and C gives interesting results. The temperature range 550-750 K can be applied to small scale power and heat energy storages in residential applications. Intermediate temperatures can be utilized at power plant scale with parabolic trough technology plants. The temperature range 750-950 K corresponds to temperatures reached in concentrated solar towers and parabolic dishes. This double source integration (power/heat) enables the compensation of variations in the availability of one source, increasing the contribution of the other. Although the analyses presented herein have shown integrations in the charge or discharge cycles as being independent, they could be combined in function of the availability of resources and operation strategy.

\section{ECONOMIC ANALYSIS}

This section presents an economic analysis based on the gross estimation of investment and operational costs, in terms of $\angle C O E$, which is defined as the normalized energy cost that provides a Net Present Value (NPV) equal to capital and operational expenditures throughout the lifetime of the analyzed system. $L C O E$ is expressed as [40]:

$$
L C O E=\frac{I+L_{\mathrm{e}}+M+R+F}{E_{1} \times \sum_{i=1}^{n} \frac{1}{(1+r)^{i}}}
$$

where $I$ refers to capital expenditure (USD/MWh), $L_{\mathrm{e}}$ is the energy cost (USD), $M$ is maintenance expenditures (USD), $R$ is repair expenditures (USD), $F$ is the financial cost (USD), $E_{1}$ refers to the annual energy produced (MWh/year), $r$ is the discount rate, and $n$ is the lifetime considered.

Table 7 shows the annual energy balance and estimated costs for a $100 \mathrm{MW}$ reference plant with daily storage discharge hours, and operating with an additional heat supply at $550 \mathrm{~K}$. Estimated values of the equipment are extrapolated from in house data and adjusted from expressions adjusted to the evolution of the Chemical Engineering Index [41]. Charging time and power consumption for each layout corresponds to the ratio calculated.

Table 7. Estimated annual energy balance and costs for a $100 \mathrm{MW}$ plant

\begin{tabular}{ccccccc}
\hline & $\begin{array}{c}\mathrm{A} \\
\text { Charge }\end{array}$ & $\begin{array}{c}\mathrm{A} \\
\text { Charge/ } \\
\text { discharge }\end{array}$ & $\begin{array}{c}\mathrm{D} \\
\text { Discharge }\end{array}$ & $\begin{array}{c}\mathrm{D} \\
\text { Charge/ } \\
\text { discharge }\end{array}$ & $\begin{array}{c}\mathrm{C} \\
\text { Discharge }\end{array}$ & $\begin{array}{c}\mathrm{C} \\
\text { Charge/ } \\
\text { discharge }\end{array}$ \\
\hline $\begin{array}{c}\text { Energy generated } \\
\text { [MWh/year] } \times 1,000\end{array}$ & 316.8 & 316.80 & 316.80 & 316.80 & 316.80 & 316.80 \\
$\begin{array}{c}\text { Energy consumption } \\
{[\text { MWh/year] } \times 1,000}\end{array}$ & 376.56 & 473.76 & 343.80 & 426.96 & 344.52 & 484.56 \\
$\begin{array}{c}\text { Thermal energy } \\
\text { from renewable } \\
\text { resource }\end{array}$ & 390.24 & 155.88 & 283.50 & 122.51 & 323.53 & 40.79 \\
$\begin{array}{c}\text { [MWh/year] } \times 1,000 \\
\text { Estimated investment } \\
\text { cost [M USD] } \\
\begin{array}{c}\text { O\&M costs } \\
\text { [M USD/year] }\end{array}\end{array}$ & 195.98 & 250.343 & 232.038 & 277.01 & 194.84 & 271.46 \\
$\begin{array}{c}\text { Consumed energy cost } \\
\text { [M USD/year] }\end{array}$ & 7.91 & 7.87 & 6.96 & 8.31 & 5.84 & 8.14 \\
\hline
\end{tabular}


In this analysis for Layout $\mathrm{D}$ the additional costs associated safety issues for ammonia cycle have not been included, and they will slightly penalize the outcomes of this layout. Annual energy costs for the charge cycle were those associated with off-peak periods. Considering the daily electricity market pool in Spain for year 2015, the mean tariff for off-peak electricity was $21 \mathrm{USD} / \mathrm{MWh}$. Figure 15 shows $L C O E$ along with the estimated annual thermal energy supplied by the low temperature solar source for the different layouts. Most of the values presented herein are below the ones presented in [42] for CAES and Pumped Hydroenergy Storage (PHS). There is a clear economic interest in advancing in the study of these integrations.

LEVELIZED COST OF ELECTRICITY

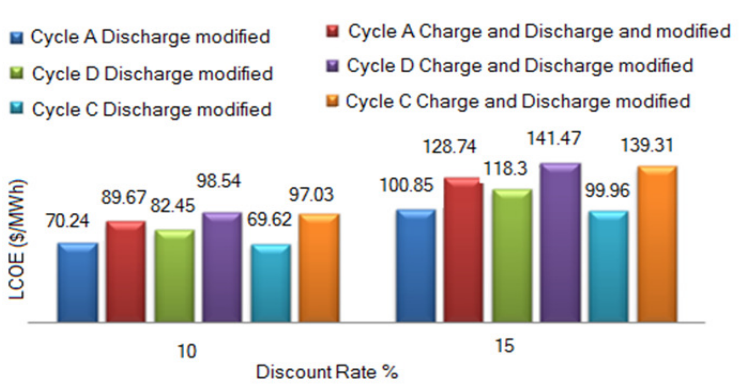

ANNUAL THERMAL ENERGY FROM RENEWABLE RESOURCE

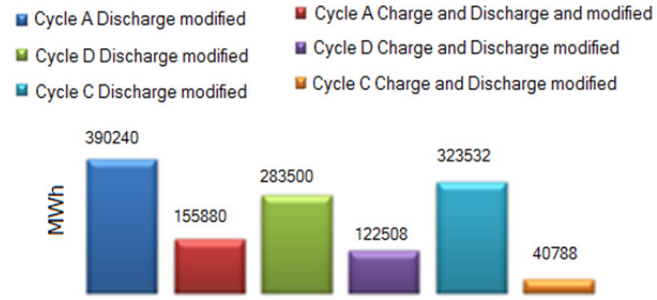

Figure 15. Estimated annual thermal energy from renewable resource and $L C O E$ for Layouts A, C and D

\section{CONCLUSIONS}

This manuscript addressed the concept of thermoelectric energy storage, using surplus electricity for thermal energy storage based on the use of a transcritical $\mathrm{CO}_{2}$ cycle, which was extended herein through the integration of local thermal energy storage. The integrated concept combines power/heat storage using electricity and thermal energy as sources. Electricity can be originated from surplus capacity of the electric grid or produced at local generation devices (wind, PV). Thermal energy sources include solar, biomass or geothermal (cold side). The combined integration presents synergies and advances in comparison with separate systems for power or heat storage. The systems proposed herein enable integration, within a single system, of different renewable sources such as wind or solar, operating at different temperature ranges and for different applications, from residential to power plant scales. Depending on the temperature range and application, different solar technologies and strategies should be considered.

Among the layouts analysed herein, Layout $\mathrm{C}$, which presented modifications in the discharge cycle only, presented the best economic performance, although required a higher thermal energy contribution. Generally, when thermal resource availability is limited, the most adequate option is to modify both charge and discharge cycles. Then selection will depend on the complexity and thermal resource availability. The lowest $L C O E$ value was obtained for Layout $\mathrm{C}$, due to lower investment costs as the power required by the compressor and turbine are smaller. However, these devices require higher thermal energy contribution. Modifications of both charge and discharge cycles provided higher compressor outlet temperatures during the charge cycle, and a lower contribution of the additional solar thermal resource was required. For temperatures between $550 \mathrm{~K}$ and $750 \mathrm{~K}$, simultaneous variation of both charge/discharge cycles could improve results. However, when considering higher temperatures, 750-950 K, modifications in the charge cycle for Layouts $\mathrm{C}$ or $\mathrm{D}$ did not result in an advantage.

The $L C O E$ values obtained herein were in the range 90-140 USD/MWh. Global analysis highlighted the interest of advancing in the study and definition of $\mathrm{TCO}_{2}$-TESS technologies, probably integrated with solar power plants for the exploitation of possible 
synergies. The integration within solar thermal power plants could convert these into regulated power plants, which compensate peak/off peak periods, either at the electric grid scale or for residential/district levels, integrating distributed generation technologies.

\section{ACKNOWLEDGMENT}

This work was supported as part of the ClimACT project (SOE1/P3/P0429EU) within the InterregSudoe Programme, funded by European Regional Development Funds.

\section{NOMENCLATURE}

$C O P_{\mathrm{HP}}$

$E_{\text {excess }}$

$h_{\mathrm{CS}}$

$h_{\mathrm{HS}}$

$\dot{Q}_{\mathrm{CS} ; \mathrm{HP}}$

$\dot{Q}_{\mathrm{CS} ; \mathrm{TE}}$

$\dot{Q}_{\mathrm{HS} ; \mathrm{HP}}$

$\dot{Q}_{\mathrm{HS} ; \mathrm{TE}}$

$R_{\text {com }}$

$R_{\text {exp }}$

$T_{\mathrm{FC}}$

$T_{\mathrm{FF}}$

$\dot{W}_{\mathrm{B}}$

$\dot{W}_{\mathrm{C}}$

$\dot{W}_{\mathrm{T}}$

$\dot{W}_{\text {TA }}$

$\dot{W}_{\text {TB }}$

$\dot{W}_{\mathrm{TH}}$

$X_{\mathrm{NH}_{3}}$

\section{Greek letters}

$\eta_{\text {ex;C }}$

$\eta_{\text {mech }}$

$\eta_{\mathrm{RT}}$

$\eta_{\mathrm{TE}}$

\section{Abbreviations}

\section{CAES}

CS

HP

HS

LCOE

PHS

TE

TEES coefficient of performance

surplus energy stored

charge/discharge hours ratio, hot side

charge/discharge hours ratio, cold side

heat transferred during the charge cycle, cold side

heat transferred during the discharge cycle, cold side

heat transferred during the charge cycle, hot side

heat transferred during the discharge cycle, hot side

compression ratio

expansion ratio

hot source temperature

cold source temperature

pump power consumption

compressor power consumption

turbine power during discharge

high pressure turbine power

low pressure turbine power

hydraulic turbine power

mass flow ratio between $\mathrm{NH}_{3}$ and $\mathrm{CO}_{2}$

exergy efficiency

mechanical efficiency

round trip efficiency

thermal engine efficiency

Compressed Air Energy Storage

Cold Storage

Heat Pump

Hot Storage

Levelized Cost of Electricity

Pumped Hydroenergy Storage

Thermal Engine

Thermoelectric Energy Storage

\section{REFERENCES}

1. Ippolito, M. G., Di Silvestre, M. L., Riva Sanseverino, E., Zizzo, G. and Graditi, G., Multi-objective Optimized Management of Electrical Energy Storage Systems in an Islanded Network with Renewable Energy Sources under Different Design Scenarios, 
Energy, Vol. 64, pp 648-662, 2014, https://doi.org/10.1016/j.energy.2013.11.065

2. Pape, C., Hagemann, S. and Weber, C., Are Fundamentals Enough? Explaining Price Variations in the German Day-ahead and Intraday Power Market, Energy Economics, Vol. 54, pp 376-387, 2016, https://doi.org/10.1016/j.eneco.2015.12.013

3. Christidis, A., Koch, C., Pottel, L. and Tsatsaronis, G., The Contribution of Heat Storage to the Profitable Operation of Combined Heat and Power Plants in Liberalized Electricity Markets, Energy, Vol. 41, No. 1, pp 75-82, 2012, https://doi.org/10.1016/j.energy.2011.06.048

4. Manz, D., Piwko, R. and Miller, N., Look Before You Leap: The Role of Energy Storage in the Grid, IEEE Power and Energy Magazine, Vol. 10, No. 4, pp 75-84, 2012, https://doi.org/10.1109/MPE.2012.2196337

5. Pan, H., Hu, Y. S. and Chen, L., Room-temperature Stationary Sodium-ion Batteries for Large-scale Electric Energy Storage, Energy \& Environmental Science, Vol. 6, No. 8, p 2338, 2013, https://doi.org/10.1039/c3ee40847g

6. Lund, H., Large-scale Integration of Wind Power into Different Energy Systems, Energy, Vol. 30, No. 13, pp 2402-2412, 2005, https://doi.org/10.1016/j.energy.2004.11.001

7. Prasad, A. R. and Natarajan, E., Optimization of Integrated Photovoltaic-wind Power Generation Systems with Battery Storage, Energy, Vol. 31, No. 12, pp 1607-1618, 2006, https://doi.org/10.1016/j.energy.2005.10.032

8. Bolund, B., Bernhoff, H. and Leijon, M., Flywheel Energy and Power Storage Systems, Renewable and Sustainable Energy Reviews, Vol. 11, No. 2, pp 235-258, 2007, https://doi.org/10.1016/j.rser.2005.01.004

9. Shukla, A. K., Sampath, S. and Vijayamohanan, K., Electrochemical Supercapacitors: Energy Storage Beyond Batteries, Current Science, Vol. 79, No. 12, pp 1656-1661, 2000.

10. Lund, H. and Salgi, G., The Role of Compressed Air Energy Storage (CAES) in Future Sustainable Energy Systems, Energy Conversion and Management, Vol. 50, No. 5, pp 1172-1179, 2009, https://doi.org/10.1016/j.enconman.2009.01.032

11. [Anagnostopoulos, J. S. and Papantonis, D. E., Pumping Station Design for a Pumped-storage Wind-hydro Power Plant, Energy Conversion and Management, Vol. 48, No. 11, pp 3009-3017, 2007, https://doi.org/10.1016/j.enconman.2007.07.015

12. Agbossou, K., Kolhe, M., Hamelin, J. and Bose, T. K., Performance of a Stand-Alone Renewable Energy System Based on Energy Storage as Hydrogen, IEEE Transactions on Energy Conversion, Vol. 19, No. 3, pp 633-640, 2004, https://doi.org/10.1109/TEC.2004.827719

13. Tian, Y. and Zhao, C. Y., A Review of Solar Collectors and Thermal Energy Storage in Solar Thermal Applications, Applied Energy, Vol. 104, pp 538-553, 2013, https://doi.org/10.1016/j.apenergy.2012.11.051

14. Yang, Z. and Garimella, S. V., Cyclic Operation of Molten-salt Thermal Energy Storage in Thermoclines for Solar Power Plants, Applied Energy, Vol. 103, pp 256-265, 2013, https://doi.org/10.1016/j.apenergy.2012.09.043

15. Chacartegui, R., Vigna, L., Becerra, J. A. and Verda, V., Analysis of Two Heat Storage Integrations for an Organic Rankine Cycle Parabolic Trough Solar Power Plant, Energy Conversion and Management, Vol. 125, pp 353-367, 2016, https://doi.org/10.1016/j.enconman.2016.03.067

16. Kuravi, S., Trahan, J., Goswami, D. Y., Rahman, M. M. and Stefanakos, E. K., Thermal Energy Storage Technologies and Systems for Concentrating Solar Power Plants, Progress in Energy and Combustion Science, Vol. 39, No. 4, pp 285-319, 2013, https://doi.org/10.1016/j.pecs.2013.02.001

17. Medrano, M., Gil, A., Martorell, I., Potau, X. and Cabeza, L. F., State of the Art on High-temperature Thermal Energy Storage for Power Generation, Part 2 - Case Studies, Renewable and Sustainable Energy Reviews, Vol. 14, No. 1, pp 56-72, 2010, 
https://doi.org/10.1016/j.rser.2009.07.036

18. Farid, M. M., Khudhair, A. M., Razack, S. A. K. and Al-Hallaj, S., A Review on Phase Change Energy Storage: Materials and Applications, Energy Conversion and Management, Vol. 45, No. 9-10, pp 1597-1615, 2004, https://doi.org/10.1016/j.enconman.2003.09.015

19. Chacartegui, R., Alovisio, A., Ortiz, C., Valverde, J. M., Verda, V. and Becerra, J. A., Thermochemical Energy Storage of Concentrated Solar Power by Integration of the Calcium Looping Process and a $\mathrm{CO}_{2}$ Power Cycle, Applied Energy, Vol. 173, pp 589-605, 2016, https://doi.org/10.1016/j.apenergy.2016.04.053

20. Alovisio, A., Chacartegui, R., Ortiz, C., Valverde, J. M. and Verda, V., Optimizing the CSP-Calcium Looping Integration for Thermochemical Energy Storage, Energy Conversion and Management, Vol. 136, pp 85-98, 2017, https://doi.org/10.1016/j.enconman.2016.12.093

21. Ortiz, C., Chacartegui, R., Valverde, J. M., Alovisio, A. and Becerra, J. A., Power Cycles Integration in Concentrated Solar Power Plants with Energy Storage Based on Calcium Looping, Energy Conversion and Management, Vol. 149, pp 815-829, 2017, https://doi.org/10.1016/j.enconman.2017.03.029

22. Parameshwaran, R., Kalaiselvam, S., Harikrishnan, S. and Elayaperumal, A., Sustainable Thermal Energy Storage Technologies for Buildings: A Review, Renewable and Sustainable Energy Reviews, Vol. 16, No. 5, pp 2394-2433, 2012, https://doi.org/10.1016/j.rser.2012.01.058

23. de Gracia, A. and Cabeza, L. F., Phase Change Materials and Thermal Energy Storage for Buildings, Energy and Buildings, Vol. 103, pp 414-419, 2015, https://doi.org/10.1016/j.enbuild.2015.06.007

24. Waqas, A. and Ud Din, Z., Phase Change Material (PCM) Storage for Free Cooling of Buildings-A Review, Renewable and Sustainable Energy Reviews, Vol. 18, pp 607-625, 2013, https://doi.org/10.1016/j.rser.2012.10.034

25. Zhang, Y., Yang, K., Hong, H., Zhong, X. and Xu, J., Thermodynamic Analysis of a Novel Energy Storage System with Carbon Dioxide as Working Fluid, Renewable Energy, Vol. 99, pp 682-697, 2016, https://doi.org/10.1016/j.renene.2016.07.048

26. Henchoz, S., Buchter, F., Favrat, D., Morandin, M. and Mercangöz, M., Thermoeconomic Analysis of a Solar Enhanced Energy Storage Concept Based on Thermodynamic Cycles, Energy, Vol. 45, No. 1, pp 358-365, 2012, https://doi.org/10.1016/j.energy.2012.02.010

27. Morandin, M., Maréchal, F., Mercangöz, M. and Buchter, F., Conceptual Design of a Thermo-electrical Energy Storage System Based on Heat Integration of Thermodynamic Cycles - Part B: Alternative System Configurations, Energy, Vol. 45, No. 1, pp 386-396, 2012, https://doi.org/10.1016/j.energy.2012.03.033

28. Akbari, A. D. and Mahmoudi, S. M. S., Thermoeconomic Performance and Optimization of a Novel Cogeneration System using Carbon Dioxide as Working Fluid, Energy Conversion and Management, Vol. 145, pp 265-277, 2017, https://doi.org/10.1016/j.enconman.2017.04.103

29. Morandin, M., Mercangöz, M., Hemrle, J., Maréchal, F. and Favrat, D., Thermoeconomic Design Optimization of a Thermo-electric Energy Storage System Based on Transcritical $\mathrm{CO}_{2}$ Cycles, Energy, Vol. 58, pp 571-587, 2013, https://doi.org/10.1016/j.energy.2013.05.038

30. Kim, Y.-M., Shin, D.-G., Lee, S.-Y. and Favrat, D., Isothermal Transcritical $\mathrm{CO}_{2}$ Cycles with TES (Thermal Energy Storage) for Electricity Storage, Energy, Vol. 49, pp 484-501, 2013, https://doi.org/10.1016/j.energy.2012.09.057

31. Vinnemeier, P., Wirsum, M., Malpiece, D. and Bove, R., Integration of Heat Pumps into Thermal Plants for Creation of Large-scale Electricity Storage Capacities, Applied Energy, Vol. 184, pp 506-522, 2016, https://doi.org/10.1016/j.apenergy.2016.10.045

32. Frate, G. F., Antonelli, M. and Desideri, U., A Novel Pumped Thermal Electricity 
Storage (PTES) System with Thermal Integration, Applied Thermal Engineering, Vol. 121, pp 1051-1058, 2017, https://doi.org/10.1016/j.applthermaleng.2017.04.127

33. Guo, J., Cai, L., Chen, J. and Zhou, Y., Performance Optimization and Comparison of Pumped Thermal and Pumped Cryogenic Electricity Storage Systems, Energy, Vol. 106, pp 260-269, 2016, https://doi.org/10.1016/j.energy.2016.03.053

34. Ayachi, F., Tauveron, N., Tartière, T., Colasson, S. and Nguyen, D., Thermo-Electric Energy Storage Involving $\mathrm{CO}_{2}$ Transcritical Cycles and Ground Heat Storage, Applied Thermal Engineering, Vol. 108, pp 1418-1428, 2016, https://doi.org/10.1016/j.applthermaleng.2016.07.063

35. Obi, M., Jensen, S. M., Ferris, J. B. and Bass, R. B., Calculation of Levelized Costs of Electricity for Various Electrical Energy Storage Systems, Renewable and Sustainable Energy Reviews, Vol. 67, pp 908-920, 2017, https://doi.org/10.1016/j.rser.2016.09.043

36. Berrada, A., Loudiyi, K. and Zorkani, I., System Design and Economic Performance of Gravity Energy Storage, Journal of Cleaner Production, Vol. 156, pp 317-326, 2017, https://doi.org/10.1016/j.jclepro.2017.04.043

37. Cahn, R. P., Thermal Energy Storage by Means of Reversible Heat Pumping, US4089744 A, United States Patent, 1976.

38. Mercangöz, M., Hemrle, J., Kaufmann, L., Z'Graggen, A. and Ohler, C., Electrothermal Energy Storage with Transcritical $\mathrm{CO}_{2}$ Cycles, Energy, Vol. 45, No. 1, pp 407-415, 2012, https://doi.org/10.1016/j.energy.2012.03.013

39. Song, Y., Wang, J., Dai, Y. and Zhou, E., Thermodynamic Analysis of a Transcritical $\mathrm{CO}_{2}$ Power Cycle Driven by Solar Energy with Liquified Natural Gas as its Heat Sink, Applied Energy, Vol. 92, pp 194-203, 2012, https://doi.org/10.1016/j.apenergy.2011.10.021

40. Sánchez, D., Frej, H., Muñoz de Escalona, J. M., Chacartegui, R. and Sánchez, T., Alternative Approach to Determining the Preferred Plant Size of Parabolic Trough CSP Power Plants, Proceedings of the ASME 2011 Turbo Expo: Turbine Technical Conference and Exposition, Vancouver, Canada, pp 1053-1062, 2011.

41. Boehm, R. F., Design Analysis of Thermal Systems, John Wiley \& Sons, New York, USA, 1987.

42. Akhil, A. A., Huff, G., Currier, A. B., Kaun, B. C., Rastler, D. M., Chen, S. B., Cotter, A. L., Bradshaw, D. T. and Gauntlett, W. D., Electricity Storage Handbook in Collaboration with NRECA, Sandia Report, Sandia National Laboratories, Albuquerque, New Mexico 87185 and Livermore, California 94550, USA, 2013. 